\title{
Intangible Assets and Cross-Sectional Stock Returns: Evidence from Structural Estimation *
}

\author{
Erica X.N. $\mathrm{Li}^{\dagger} \quad$ Laura X.L. Liu ${ }^{\ddagger}$
}

December 22, 2012

\begin{abstract}
The relation between a firm's stock return and its intangible assets is derived under the intangible-asset-augmented $q$-theory framework. The structural estimation of the model leads to four main results. First, the $q$-theory augmented with intangible investments captures the value premium and the relation between R\&D intensity and stock returns significantly better than the conventional $q$-theory. Two features of intangible assets, adjustment costs and investment-specific-technological-change, are crucial to the improved model performance. Second, higher R\&D intensity, defined as the ratio of R\&D expenditure to intangible assets, leads to lower stock returns. Third, the $q$-theory augmented with intangible investments gives a more reasonable estimate of adjustment costs of tangible investments than the conventional $q$-theory does. Fourth, the magnitude of adjustment costs of R\&D investments is estimated to be larger than that of tangible investments.
\end{abstract}

JEL Classification: C51, G12, O31, O32

Keywords: investment-based asset pricing, intangible assets, structural estimation, R\&D

${ }^{*}$ We benefit from the discussion with Sudipto Dasgupta, Phil Dybvig, Jinyu He, Po-Hsuan Hsu, Vidhan Goyal, Jing-Ming Kuo, Mike Lemmon, Nan Li, Tao Li, Peter Mackey, Jianjun Miao, Mark Seasholes, Maciej Szefler, Congyan Tan, Peng Wang, Yong Wang, John Wei, Chu Zhang, Hong Zhang, and Lu Zhang. For helpful comments we thank the seminar participants at City University of Hong Kong, Cheung Kong Graduate School of Business, the Hong Kong University of Science and Technology, the University of Hong Kong, and the University of Michigan, Shanghai University of Finance and Economics, Asian Finance Association International Conference 2010, European Financial Management Symposium 2011, Summer Institute of Finance, 2011, China International Conference in Finance, 2011. We acknowledge the financial support from Hong Kong RGC Competitive Earmarked Research Grant (Grant No: 643611). All remaining errors are our own.

${ }^{\dagger}$ Finance Department, Cheung Kong School of Business, Beijing, China; Tel: (8610) 88188858 exit 3075; Fax: (8610) 85186800; E-mail: xnli@ckgsb.edu.cn.

${ }^{\ddagger}$ Finance Department, School of Business and Management, Hong Kong University of Science and Technology, The Clearwater Bay, Hong Kong; Tel: (852) 2358-7661; Fax: (852) 2358-1749; E-mail: laura.xiaolei.liu@ust.hk. 


\section{Introduction}

Intangible assets have been widely recognized as the driving force of an economy's productivity growth and have become more and more crucial for a firm's survival and prosperity. Recent studies (Rauh and Suf, 2010; Rampini and Viswanathan, 2010) show that a firm's asset tangibility is an important determinant for corporate policies, such as capital structure. However, less attention has been paid to the impact of intangible assets on stock returns, with the exception of Chan, Lakonishock, and Sougiannis (2001) (CLS) among others. In this study, we explore the relation between intangible assets and stock returns, both theoretically and empirically, and quantify the characteristics of intangible assets based on the structural estimation of our theoretical model.

We build a $q$-theory model with both tangible and intangible assets where investments in both types of assets incur adjustment costs and the accumulation of intangible assets leads to increased productivity of intangible investment, the so called "investment-specific technological change (ISTC)" effect. Adjustment costs prevent firms from accumulating assets rapidly. The magnitude of adjustment costs hence determines the speed of capital growth and the persistence of industry incumbents' profitability. The ISTC effect of intangible assets has been widely used to explain the productivity growth of an economy at the aggregate level (Greenwood, Hercowitz, and Krusell, 1997). In this paper, we study the impacts of both the adjustment cost (AC) effect of intangible investment and the ISTC effect on stock returns. More importantly, we quantify the magnitudes of the adjustment costs of both tangible and intangible assets and the magnitude of the ISTC effect based on the estimation of the model.

The structural estimation is based on the relation between a firm's stock return and its observable characteristics: both tangible and intangible investment rates, asset tangibility, profitability,

and leverage, derived from our theoretical model. By matching the model predicted stock returns with the realized returns, we estimate the model parameters and compare the performance of the intangible-asset-augmented $q$-theory (the IAA $q$-theory) with that of the conventional $q$-theory using three sets of testing portfolios. Due to the data availability (Lev, 2001), we focus on one special type of intangible investments, research and development (R\&D) expenditure, and construct the level of intangible assets based on the accumulation of past R\&D expenditures. The three sets of testing portfolios are portfolios sorted by the book-to-market ratio, the R\&D-to-intangible-asset ratio, and the R\&D-to-market-equity ratio, respectively.

The main findings of the paper are as follows. First, the non-nested tests indicate that the IAA $q$-theory explains cross-sectional stock returns significantly better than the $q$-theory with only tangible asset across all three sets of testing portfolios. Moreover, both the AC effect and the ISTC effect of intangible assets are shown by the nested tests to be crucial to the improved 
explanatory power.

Second, we show that high R\&D-intensive firms earn $10 \%$ higher stock returns per annum, with $t$-statistic being 4.03, than low R\&D-intensive firms, using the model implied measure of R\&D intensity, R\&D-to-intangible-assets ratio. This finding overhauls the widely documented "puzzle" that high physical investment-intensive firms earn lower returns (Titman, Wei, and Xie, 2004, henceforth TWX), however high R\&D-intensive firms earn higher returns (CLS). We show that this "puzzle" is due to the fact that R\&D intensity used in CLS uses market value of equity as the scaler, while tangible investment intensity used in the literature use either PP\&E (proxy for physical assets) or total assets as scaler. ${ }^{1}$ Our theory implies that in the relation with stock returns, R\&D-to-intangible-assets ratio plays a similar role as the investment-to-physical-assets ratio and should be the more suitable measure of R\&D intensity. Our empirical evidence shows that the R\&D-to-intangible-assets ratio is indeed negatively related to stock returns, the same as the relation between tangible investment ratio and stock returns documented in the literature.

Third, the IAA $q$-theory implies a $19.88 \%$ adjustment-costs-to-investment ratio (the $A C / I$ ratio) for capital investments, averaging across all three sets of testing portfolios, while the estimates of the conventional $q$-theory is $223 \%$. The existing literature estimates the $A C / I$ ratio either using simulation of calibrated models (Summers, 1981; Cooper and Haltiwanger, 2006), or using reduced-form regression of investment data (Litchenberg, 1988). The estimates from the aforementioned three papers are $22.1 \%, 20.0 \%$, and $33.09 \%$, respectively. Therefore, using both stock return data and investment data, the structural estimation of the IAA $q$-theory model leads to a much closer estimate of the $A C / I$ ratio to what the previous literature finds than the conventional $q$-theory does.

Last, the model implies a larger $A C / I$ ratio for intangible investments than that for tangible investments. This finding provides empirical support for the conventional wisdom that intangible assets are more crucial for firms to sustain their comparative advantages than tangible assets because it is more costly to accumulate intangible assets rapidly.

Our paper contributes to several strands of literature. There is a large literature that attempts to capture the cross-sectional returns using the investment-based asset pricing model (Cochrane, 1996; Liu, Whited, and Zhang, 2009; Belo, Lin and Vitorino, 2012, Vitorino, 2012). Our paper contributes to this literature by introducing intangible assets into the investment-based asset pricing.

Our paper contributes to the literature that studies the impact of R\&D investments on stock returns both empirically such as Li (2007), Hsu (2009), and Hirshleifer, Hsu (2011) among others,

\footnotetext{
${ }^{1}$ TWX study abnormal capital investment growth, where capital investment is measured as investments scaled by PP\&E.
} 
and theoretically such as Lin (2012). This paper differs from previous work in that it considers adjustment costs of investments, in addition to the ISTC effect in the model and conducts structural estimation of the model instead of using reduced form approach.

Our work is also related to the growing field that uses structural estimation to study external financing costs, financial constraints, private benefits of control or cross-sectional stock returns ((Hennessy and Whited, 2007; Whited and Wu, 2006; Albuquerque and Schroth, 2010; Liu, Whited, and Zhang, 2009). Our work uses this framework to study firm's R\&D investments.

More generally, our paper provides a new methodology to the literature that studies the distinctive features of intangible assets. The macroeconomics literature focuses on how the investmentspecific technological change affects productivity growth at the aggregate level using model calibration (Greenwood, Hercowitz, and Krusell, 1997; Huffman, 2007). The literature in organization science and evolutionary economics is devoted to understand how the accumulation process of intangible assets shapes the structure of an industry and the survival rate of new entrants into the industry (Knott, Bryce and Posen, 2003). This paper, to our best knowledge, is the first paper to quantify the magnitudes of the adjustment costs of $\mathrm{R} \& \mathrm{D}$ investments and the ISTC effect using asset return data and using structural estimations.

\section{The Model}

Assume that a firm faces infinite horizon and the time is discrete. The firm's production requires both tangible and intangible capital/assets in addition to non-capital input. Let $Y_{j t}$ denotes the revenue of firm $j$ at time $t$

$$
Y_{j t}=e^{X_{t}}\left[\left(K_{j t}^{m}\right)^{\gamma}\left(K_{j, t}^{u}\right)^{1-\gamma}\right]^{\alpha}\left(L_{j t}\right)^{1-\alpha}
$$

where $K_{j, t}^{m}$ is the capital stock of tangible assets, $K_{j, t}^{u}$ is the capital stock of intangible assets, $X_{t}$ is the exogenous productivity shock, $\alpha$ is the capital-to-output, and $\gamma$ is the elasticity of substitution between tangible and intangible assets. ${ }^{2}$ Without loss of generality, let $L_{j t}$ be the non-capital factor input and assume that firm $j$ is a price taker in the input markets. We assume constant-return-to-scale Cobb-Douglas production function. The accumulations of tangible assets

\footnotetext{
${ }^{2}$ The model applies to any form of intangible investments even though the empirical study in the paper focuses on one specific form, i.e., R\&D investments.
} 
and intangible assets follow

$$
\begin{aligned}
& K_{j t+1}^{m}=\left(1-\delta_{m, j t}\right) K_{j t}^{m}+I_{j t}^{m}, \\
& K_{j t+1}^{u}=\left(1-\delta_{u, j t}\right) K_{j t}^{u}+\Theta\left(I_{j t}^{u}, K_{j t}^{u}\right),
\end{aligned}
$$

where $I_{j t}^{m}$ and $I_{I, t}^{u}$ are the investments made by firm $j$ at time $t$ in tangible assets and intangible assets, respectively, and $\delta_{m, j t}$ and $\delta_{u, j t}$ are the corresponding depreciation rates. Both tangible and intangible investments are produced using final outputs. The production function of the new intangible assets, $\Theta$, is defined as

$$
\Theta_{j t} \equiv \Theta\left(I_{t}^{u}, K_{t}^{u}\right)=\left[a_{1}\left(I_{t}^{u}\right)^{\xi}+a_{2}\left(K_{t}^{u}\right)^{\xi}\right]^{1 / \xi}
$$

with positive constants $\xi, a_{1}$ and $a_{2}$ so that the amount of newly produced intangible assets increases with the levels of both intangible investments and existing intangible assets. Moreover, with $\xi<1$, the productivity of the intangible investments increases with the level of the existing intangible assets of firm $j$.

To better understand the economic intuition behind the production function of intangible assets, we rewrite $\Theta$ as

$$
\Theta_{j t}=I_{t}^{u} Q_{t}^{u} \quad \text { and } \quad Q_{t}^{u}=\left[a_{1}+a_{2}\left(\frac{K_{t}^{u}}{I_{t}^{u}}\right)^{\xi}\right]^{1 / \xi}
$$

where $Q_{t}^{u}$ measures the amount of new intangible assets that can be produced from one dollar of intangible investment at time $t$ and the time series of $Q_{t}^{u}$ represents the progress of investmentspecific technological changes (ISTC). ${ }^{3}$

We can see that as a firm accumulates more intangible assets, intangible investments become more productive in generating new intangible assets, or equivalently, the dollar price of the new intangible assets, $1 / Q_{t}^{u}$, decreases. Our formulation of the production of intangible assets captures the intuition that the accumulation of knowledge capital makes generating new knowledge less expensive.

\footnotetext{
${ }^{3}$ The ISTC effect in the macroeconomic literature pioneered by Greenwood, Hercowitz, and Krusell (1997) appears in the accumulation of quality-adjusted physical capital. Since there is no data on quality-adjusted physical capital at the firm level, we put the ISTC effect in the accumulation of intangible assets, which we believe captures the same economic intuition, and use the the book values of physical assets.
} 
Both investments in tangible assets and in intangible assets incur adjustment costs

$$
\begin{aligned}
\Phi_{j t}^{m} & \equiv \Phi^{m}\left(I_{j t}^{m}, K_{j t}^{m}\right)=\frac{a}{2}\left(\frac{I_{j t}^{m}}{K_{j t}^{m}}\right)^{\rho} K_{j t}^{m}, \\
\Phi_{j t}^{u} & \equiv \Phi^{u}\left(I_{j t}^{u}, K_{j t}^{u}\right)=\frac{b}{2}\left(\frac{I_{j t}^{u}}{K_{j t}^{u}}\right)^{\psi} K_{j t}^{u},
\end{aligned}
$$

where $a, b, \rho$ and $\psi$ are positive constants, with the first two constants reflecting the magnitude of the adjustment costs and the latter two constants reflecting the curvature of the adjustment costs for tangible investments and intangible investments, respectively.

Firms are allowed to have both equity and debt financing, both of which incur no costs. Following Hennessy and Whited (2007) and Liu, Whited, and Zhang (2009) (henceforth LWZ), we assume that firms issue one-period debt. The debt outstanding of firm $j$ is $B_{j t}$ at the beginning of period $t$, with the gross required return $r_{j t}^{B}$. At the end of period $t$, firm $j$ issues a new debt with outstanding $B_{j t+1}$. The net cash flow accrued to the shareholders of firm $j$ is

$D_{j t}^{S}=\left(1-\tau_{j t}\right)\left(Y_{j t}-\varpi_{t} L_{j t}-\Phi_{j t}^{m}-\Phi_{j t}^{u}-I_{j t}^{u}\right)-I_{j t}^{m}+\tau_{j t} \delta_{m, j t} K_{j t}^{m}-\left[1+\left(r_{t}^{B}-1\right)\left(1-\tau_{t}\right)\right] B_{j t}+B_{j t+1}$,

where $\varpi_{t}$ is the price on non-capital input and $\tau_{j t}$ is the corporate tax rate on firm $j$ at time $t$.

We solve the maximization problem of a representative firm $j$ and write its investment return as a function of firm's observable characteristics. To simplify the notation, we omit subscript $j$ in all the equations where no ambiguity is present.

Proposition 1. Firm's investment return $r_{t+1}^{I}$, defined as

$$
\begin{aligned}
r_{t+1}^{I}= & \left\{\left(1-\tau_{t+1}\right) \frac{\alpha Y_{t+1}}{K_{t+1}^{m}}+\tau_{t+1} \delta_{m, t+1}-\left(1-\tau_{t+1}\right) \Phi_{k, t+1}^{m}+\left(1-\delta_{m, t+1}\right)\left[1+\left(1-\tau_{t+1}\right) \Phi_{I, t+1}^{m}\right]\right. \\
& \left.+\left[\left(1-\tau_{t+1}\right)\left(1+\Phi_{i, t+1}^{u}\right)\right]\left(\frac{\Theta_{K, t+1}}{\Theta_{I, t+1}}\right)-\left(1-\tau_{t+1}\right) \Phi_{K, t+1}^{u}+\frac{\left(1-\delta_{u, t+1}\right)\left(1-\tau_{t+1}\right)\left(1+\Phi_{i, t+1}^{u}\right)}{\Theta_{I, t+1}}\right] \\
& \left.\times\left(\frac{K_{t+1}^{u}}{K_{t+1}^{m}}\right)\right\} /\left\{\left[1+\left(1-\tau_{t}\right) \Phi_{I, t}^{m}\right]+\left[\frac{\left(1-\tau_{t}\right)\left(1+\Phi_{I, t}^{u}\right)}{\Theta_{I, t}}\right]\left(\frac{K_{t+1}^{u}}{K_{t+1}^{m}}\right)\right\},
\end{aligned}
$$

satisfies

$$
\mathbb{E}_{t}\left[M_{t+1} \mathbb{I}_{t+1} r_{t+1}^{I}\right]=1
$$

where $M_{t+1}$ is the stochastic discount factor from $t$ to $t+1 . r_{t+1}^{I}$ is equal to the weighted average 
of the return on firm's equity and the after-tax return on its debt,

$$
r_{t+1}^{I}=\left(1-w_{t}\right) r_{t+1}^{S}+w_{t} r_{t+1}^{B a}
$$

where $w_{t}$ is the ratio of debt value to firm value at the end of period $t$

$$
w_{t}=\frac{B_{t+1}}{P_{t}-D_{t}^{S}+B_{t+1}},
$$

$r_{t+1}^{S}$ is stock return from period $t$ to $t+1$

$$
r_{t+1}^{S}=\frac{P_{t+1}}{P_{t}-D_{t}^{S}}
$$

$r_{t+1}^{B a}$ is the after-tax return on debt

$$
r_{t+1}^{B a}=r_{t+1}^{B}-\tau_{t+1}\left(r_{t+1}^{B}-1\right)
$$

and $\Phi_{*, t}^{m}$ is the derivative of the adjustment cost function of tangible assets w.r.t. variable *. Similar definitions for $\Phi_{*, t}^{u}$ and $\Theta_{*, t}$.

Appendix 5 provides the proof of Proposition 1. To understand the economics behind equation (6), we decompose firm's investment return into two components: the return on tangible assets $r_{t+1}^{I, m}$, defined as

$$
r_{t+1}^{I, m}=\frac{\left(1-\tau_{t+1}\right)\left[\alpha \frac{\gamma Y_{t+1}}{K_{t+1}^{m}}-\Phi_{K, t+1}^{m}\right]+\tau_{t+1} \delta_{m}+\left(1-\delta_{m}\right)\left[1+\left(1-\tau_{t+1}\right) \Phi_{I, t+1}^{m}\right]}{1+\left(1-\tau_{t}\right) \Phi_{I, t}^{m}}
$$

and the return on intangible assets $r_{t+1}^{I, u}$, defined as

$$
\begin{aligned}
r_{t+1}^{I, u}= & \left\{\left(1-\tau_{t+1}\right)\left[\alpha \frac{(1-\gamma) Y_{t+1}}{K_{t+1}^{u}}-\Phi_{K, t+1}^{u}\right]+\frac{\left(1-\delta_{u}\right)\left(1-\tau_{t+1}\right)\left(1+\Phi_{i, t+1}^{u}\right)}{\Theta_{I, t+1}}\right. \\
& \left.+\left(1-\tau_{t+1}\right)\left(1+\Phi_{i, t+1}^{u}\right)\left(\frac{\Theta_{K, t+1}}{\Theta_{I, t+1}}\right)\right\} /\left[\left(1-\tau_{t}\right)\left(1+\Phi_{I, t}^{u}\right) / \Theta_{I, t}^{u}\right] .
\end{aligned}
$$

A firm's investment return is a weighted average of its investment return on tangible assets and its investment return on intangible assets, with the weights being the ratio of the market value of tangible assets to total firm value and the ratio of the market value of intangible assets to total firm value, respectively. 
By definition, the return on investments is a ratio of marginal benefits of one more unit of investment to its marginal costs. The marginal benefits include the marginal free cash flow at the current period and the marginal continuation value. The marginal costs include the price of one unit of investment, which is normalized to one for both types of investments, and the marginal adjustment costs of investments.

For tangible investments, the denominator in equation (8) is the marginal cost of tangible investments at time $t$, including the price of one unit of investment, which is always 1 , and the after-tax marginal adjustment $\operatorname{costs} \Phi_{I, t}^{m}{ }^{4} \quad$ Under the assumption that $\psi>0$, the higher the investment-to-assets ratio, the larger the marginal costs of investments.

The numerator in equation (8) is the marginal benefits of tangible investments made at time $t$ The first term in the numerator is the after-tax cash flow generated at time $t+1$ from one unit of increased tangible capital, given by the first term $\alpha \gamma Y_{t+1} / K_{t+1}^{m}$, minus the marginal increase in investment adjustment costs $\Phi_{K, t+1}$. The second term is the tax benefit from the deprecation of one unit of increased capital. The last term is the marginal continuation value (i.e., the market value at $t+1$ of one unit of increased capital after depreciation). Appendix 5 shows that the market price of capital at $t+1$ (i.e., the shadow price of capital) is given by

$$
q_{t+1}^{m}=1+\left(1-\tau_{t+1}\right) \Phi_{I, t+1}^{m}
$$

Hence, the marginal continuation value of one unit tangible capital is given by

$$
\left(1-\delta_{m}\right) q_{t+1}^{m}=\left(1-\delta_{m}\right)\left[1+\left(1-\tau_{t+1}\right) \Phi_{I, t+1}^{m}\right]
$$

Compared to the return to tangible investments, the return on intangible investments shows two major differences. First, one unit of intangible investments generates more than $\Theta_{I, t}$ units of intangible assets due to the ISTC effect, which is larger than one. Hence, the cost of producing the last unit of new intangible asset is given by

$$
\frac{\left(1-\tau_{t}\right)\left(1+\Phi_{I, t}^{u}\right)}{\Theta_{I, t}} .
$$

For the same reason, Appendix 5 shows that the shadow price of the intangible asset at $t+1$ is given by

$$
q_{t+1}^{u}=\frac{\left(1-\tau_{t+1}\right)\left(1+\Phi_{I, t+1}^{u}\right)}{\Theta_{I, t+1}} .
$$

\footnotetext{
${ }^{4}$ Since the adjustment cost is categorized as part of the operating costs and it reduces a firm's taxable income, the net costs are given by $\left(1-\tau_{t}\right) \Phi_{I, t}^{m}$.
} 
Second, intangible investment is expensed, instead of capitalized as tangible investment, and hence there is a corresponding tax deduction. Finally, a firm's investment return also depends on the relative value of the tangible assets to the intangible assets that the firm has, which depends on the shadow prices for both assets and is given by $q_{t}^{m} K_{t}^{m} / q_{t}^{u} K_{t}^{u}$. Combining the value-weighted returns on tangible and intangible investments leads to the return to investments on equation (8).

Proposition 1 implies that for any firm, at any period, and in any state of the world, its realized stock return equals the model predicted levered investment return, that is,

$$
r_{t+1}^{S}=r_{t+1}^{I w} \equiv \frac{r_{t+1}^{I}-w_{t} r_{t+1}^{B a}}{1-w_{t}}
$$

where $r_{t+1}^{I w}$ is defined as the levered investment return. Through equation (6), we can relates a firm's characteristics with its stock returns, both of which are observable. Equation (10) is the equality that we use to construct the moment conditions for the structural estimation in Section 3.

Before we proceed to the empirical part of the paper, there are a couple of points that merit detailed discussion. First, our model is not a risk factor model and to derive equation (6), we do not need to specify the stochastic discount factor (SDF). The effect of the SDF is reflected implicitly on the firm's optimal corporate policies. Since we do not make any assumptions on the specific form of the SDF, the model is silent on the rationality of the investors. On the production side, the model assumes that the manager of the firm knows the SDF and makes the investment and financing decisions to maximize the shareholders' value.

Second, both returns and characteristics are endogenously determined by the exogenous factors (e.g., productivity shocks) and predetermined factors (e.g., the existing amounts of tangible and intangible assets that the firm has). Therefore, Proposition 1 gives us a relation, but not a causality, between a firm's realized stock return and its observable characteristics, such as profitability and investment rates.

\section{Structural Estimation of the Model}

In this section, we take the model to the data and investigate the importance of intangible assets in capturing cross-sectional stock returns using structural estimations. Given the data limitation, we focus on one specific type of intangible investments, R\&D investments. Based on the parameter estimates of the models, we infer the magnitude of the adjustment costs of both tangible and $R \& D$ investments. 


\subsection{Test Design and Econometric Methodology}

To investigate the importance of each feature of intangible assets in capturing the cross-sectional stock returns and to quantify the characteristics of the tangible and intangible investments, we construct and estimate four $q$-theory models: a $q$-theory model with only tangible assets (the $Q m$ model), an IAA $q$-theory model with the ISTC effect (the $Q u_{-} I S T C$ model), an IAA $q$-theory model with the AC effect (the $Q u_{-} A C$ model), and an IAA $q$-theory model with both the ISTC effect and the AC effect (the $Q u$ model). The parsimonious $Q m$ model is the model used in LWZ and is our benchmark model. Because LWZ use quadratic adjustment costs for tangible investments, for comparison reason, we set $\rho$ to be 2 for all four models. There are two parameters to be estimated for the $Q m$ model: the capital-to-output share, $\alpha$, and the tangible investment adjustment cost parameter, $a$. We set the curvature $\xi$ to be $1 / 2$ so that the productivity of the intangible investments increases with the level of the existing intangible assets and normalize $a_{1}$ to one in order to focus on the magnitude parameter of the ISTC effect, $a_{2}$. Therefore, compared with the benchmark $Q m$ model, we add one more parameter, $a_{2}$, in the $Q u_{-} I S T C$ model and two parameters, $b$ and $\psi$, in the $Q u_{-} A C$ model. Finally, there are 5 parameters to be estimated for the $Q u$ model: $\alpha, a, a_{2}, b$, and $\psi$.

Following LWZ, we test the ex-ante restriction implied by equation (7): expected stock returns equal expected levered investment return,

$$
\mathbb{E}\left[r_{i t+1}^{S}-r_{i t+1}^{I w}\right]=0
$$

for testing portfolio $i$. Define the pricing error $e_{i}$ from the above moment condition as

$$
e_{i}=\mathbb{E}_{T}\left[r_{i t+1}^{S}-r_{i t+1}^{I w}\right]
$$

where $r_{i t+1}^{S}$ is the observed stock return of portfolio $i$ at $t+1, r_{i t+1}^{I w}$ is the corresponding modelimplied levered investment return, constructed from firm characteristics using equations (6) and (7), and $\mathbb{E}_{T}$ is the sample mean of the time series in the bracket. Both measurement errors and model specification errors contribute to the pricing error $e_{i}$, which is assumed to have a mean of zero.

We use one-stage GMM with identity weighting matrix to estimate the aforementioned four models. It has been shown that the efficient two-stage GMM estimator has poorer small-sample properties than the one-stage GMM estimator with identify matrix. ${ }^{5}$ Because we use annual data

\footnotetext{
${ }^{5}$ See Hayashi (2000) page 215 for detailed discussions regarding the small-sample properties of GMM estimators.
} 
on firm characteristics and our sample only starts in 1975 for reasons detailed next, we decide to use the more robust, albeit less efficient, one-stage GMM estimation. Consequently, the corresponding set of parameter estimates is chosen to minimize the equal-weighted pricing errors of each set of the testing portfolios. To be consistent with their economic meanings, the parameters are estimated within the following ranges: $0<\alpha<1, a \geq 0, a_{2} \geq 0, b \geq 0$ and $\psi \geq 0$.

\subsection{Data}

We obtain the firm characteristics data from Standard and Poor's COMPUSTAT industrial files and the stock return data from the Center for Research in Security Prices (CRSP). The accounting treatment of the R\&D expenditure only became standard after FASB issued SFAS No. 2 in 1974 to require the full expending of $R \& D$ outlays in financial reports of public firms. To reduce possible measurement errors, we choose our sample from 1975 to 2008. We exclude firms in software industry (SIC code between 7370 and 7372), whose accounting treatment of R\&D may be different from other firms because the costs of development for software can be capitalized, according to SFAS 86. Following the literature, we also exclude the financial firms (SIC code between 6000 and 6999) and regulated utilities (SIC code between 4900 and 4999) from the sample. As being explained in details later, because we construct the level of intangible assets from past $R \& D$ expenditures, only firm-year observations with positive $R \& D$ are included in our sample. Finally, we delete firm year observations when a firm went through a major restructuring defined as acquisition amount (Compustat item AQC) is more than fifteen percent of the book value of asset. Specific definitions of the data items that we use can be found in Appendix 6 .

We use three sets of testing portfolios: ten book-to-market portfolios, ten R\&D-to-intangibleasset portfolios, and ten R\&D-to-market-equity portfolios. We choose portfolios that are likely to show a significant cross-portfolio spread of intangible assets because tests based on these portfolios are likely to be more powerful in identifying the effects of intangible assets.

Book-to-market portfolios are natural choices for testing portfolios because the book-to-market ratio $(B / M$ ratio) reflects not only the rent due to imperfect competition but also the value of intangible assets, with the later becoming more and more important in the last twenty years. Our second set of portfolios is sorted on the R\&D-to-market-equity ratio $\left(I^{u} / M E\right.$ ratio, where $M E$ stands for market equity), which by construction have large spreads on $R \& D$ and thus large spreads on the level of intangible assets. The $\mathrm{R} \& \mathrm{D}$-to-market-equity ratio is the measure of $\mathrm{R} \% \mathrm{D}$ intensity used in CLS.

The third sorting variable is the R\&D-to-intangible-assets ratio ( $I^{u} / K_{0}^{u}$ ratio, where $K_{0}^{u}$ is our proxy for intangible asset and will be defined later), which is our measure of R\&D intensity. 
Our model implies that the R\&D-to-intangible-asset ratio plays a similar role as the investmentto-tangible-asset ratio, commonly used as a measure of investment intensity, in the relation with stock return, especially when the ISTC effect is small. In the extreme case when the ISTC effect is absent, if we exchange the positions of the tangible investment and intangible investment and the positions of the tangible asset and intangible asset in equation (6), the equation stays the same. Based on this observation, the R\&D-to-intangible-asset ratio should be the measure of R\&D intensity comparable to the commonly used measure of investment intensity.

The construction of the ten book-to-market $(B / M)$ portfolios follows Fama and French (1993) and details can be found on Kenneth French's website. ${ }^{6}$ The ten R\&D-to-market-equity $\left(I^{u} / M E\right)$ portfolios are constructed in a similar manner. In June of year $t$, we sort stocks into ten portfolios based on the $I^{u} / M E$ ratio and hold the portfolios for a year. The numerator $I^{u}$ is proxied by $R \& D$ expenditure, measured at the end of the fiscal year ending in calendar year $t-1$. The denominator $M E$ is market level of equity, measured at the beginning of the same fiscal year. The portfolios are rebalanced every year.

To form the ten R\&D-to-intangible-asset $\left(I^{u} / K_{0}^{u}\right)$ portfolios, we need a proxy, labeled as $K_{0}^{u}$, for the level of intangible assets, which in theory depends on the magnitude of the ISTC effect that needs to be estimated and on the depreciation rate of intangible assets. To construct the proxy $K_{0}^{u}$, we ignore the ISTC effect, which leads to underestimation of intangible assets, and following CLS and Summers (1981), we use a depreciation rate of $20 \%$. The proxy for intangible assets at the beginning of fiscal year $t-1$ is given by

$$
K_{0, t-1}^{u}=R \& D_{t-2}+0.8 R \& D_{t-3}+0.8^{2} R \& D_{t-4}+0.8^{3} R \& D_{t-5}+0.8^{4} R \& D_{t-6}
$$

The variable $K_{0}^{u}$ incorporates only the intangible investments made in the most recent five years. Lev and Sougiannis (1996) estimate the impact of the current and past R\&D expenses on earnings. They show that the horizon of the impact varies across industries from five years to nine years. We take a low end of five years in order to keep as many observations as possible. This assumption also leads to underestimation of intangible assets.

Note that $K_{0}^{u}$ is different from the level of intangible assets, $K^{u}$, that is used in equation (6) to construct levered stock returns because $K^{u}$ incorporates the ISTC effect. To construct $K^{u}$, we also uses the most recent five years' R\&D expenditures and a depreciation rate of $20 \%$. Specifically, the value of $K_{t}^{u}$ is calculated by applying equation (2) recursively, using the R\&D expenditure starting from time $t-5$ to $t$ and assuming that $K_{t-5}^{u}$ is zero. Because the value of $a_{2}$ varies across different models, the level of intangible assets is parameter-dependent.

\footnotetext{
${ }^{6}$ We thank Kenneth French for making the data publiclly available.
} 
The timing alignment between the accounting variables used in the L.H.S. of equation (6) and the return in the R.H.S. is the same as the one used in LWZ. In general, the flow variables reflecting the economic activities over one fiscal year are measured at the end of the fiscal year while the stock variables, such as $K_{i t}^{m}$ and $K_{i t}^{u}$, are measured at the beginning of the fiscal year. The detailed description on the timing alignment can be found in Appendix C of Liu, Whited, and Zhang (2009). Finally, since we need five years' data to construct $K_{0}^{u}$ and $K^{u}$, our portfolio formation starts in June, 1980 and ends in June, 2007.

\subsection{Summary statistics on portfolio returns}

Table 1 reports summary statistics for the returns for all three groups of testing portfolios. The results for the $B / M, I^{u} / K_{0}^{u}$, and $I^{u} / M E$ portfolios are shown in Panels $\mathrm{A}, \mathrm{B}$, and $\mathrm{C}$, respectively. We report the means of the portfolio returns and the model errors (the intercepts) of the CAPM model and the Fama-French 3-factor model with their corresponding $t$-statistics.

$B / M$ portfolios. - Consistent with previous studies, the annual return is monotonically increasing with the $B / M$ ratio. The value premium (i.e., the annual buy-and-hold return spread between the firms with the highest $B / M$ and the firms with the lowest $B / M$ firms) is $15.37 \%$ per annum. $^{7}$ Neither the CAPM model nor the Fama-French 3 -factor model can capture the value premium. The pricing errors of both models are significantly different from zero.

$I^{u} / K_{0}^{u}$ portfolios. - The portfolio return decreases with the $I^{u} / K_{0}^{u}$ ratio. As argued previously, our model implies that the $I^{u} / K_{0}^{u}$ ratio is the measure of $\mathrm{R} \& \mathrm{D}$ intensity that is comparable to investment intensity. Our results show that similar to investment intensity, R\&D intensity has a negative relation with stock returns, opposite to what the previous literature documents. The average annual return spread between the firms with the highest $I^{u} / K_{0}^{u}$ ratio and the ones with the lowest $I^{u} / K_{0}^{u}$ ratio is $-10.18 \%$ per annum $(t=-4.03)$. The CAPM alpha of the high-minuslow zero-investment portfolio is $-9.46 \%$ per annum $(t=-3.39)$ and the Fama-French alpha is $-7.33 \%$ per annum $(t=-2.34)$.

$I^{u} / M E$ portfolios. - The portfolio return is increasing with the $I^{u} / M E$ ratio, consistent with what CLS document. The average return of the high-minus-low zero-investment portfolio is $24.38 \%$ per annum $(t=2.81)$. The CAPM alpha is $21.34 \%$ per annum $(t=2.23)$ and the Fama-French model alpha is $31.20 \%$ per annum $(t=3.98)$. Previous literature concludes that intangible investment and tangible investment have opposite relations with stock returns based on this measure. However, with market value of equity as denominator, this measure of $R \& D$

\footnotetext{
${ }^{7}$ This magnitude is larger than the ones reported in other studies because we use buy-and-hold compound annual return, while most of the other studies report monthly return.
} 
intensity is likely to reflect the value effect and the leverage effect in addition to the effect of $R \& D$ intensity.

In summary, all three sets of testing portfolios have large cross-portfolio return spreads, which cannot be explained by either the CAPM model or the Fama-French 3-factor model. Both the book-to-market ratio and the R\&D-to-market-equity ratio have positive relations with stock returns, while the R\&D-to-intangible-assets ratio has a negative relation with stock returns. Going forward, we refer to the R\&D-to-intangible-assets ratio $\left(I^{u} / K_{0}^{u}\right)$ as R\&D intensity.

\subsection{Summary statistics on portfolio characteristics}

Table 2 reports the summary statistics for the $B / M, I^{u} / K_{0}^{u}$, and $I^{u} / M E$ portfolios in Panels A, $\mathrm{B}$, and $\mathrm{C}$, respectively, on the following portfolio characteristics: current and future investment-tocapital ratios (investment intensity), growth rate of investment intensity, current and future R\&D intensity, growth rate of $\mathrm{R} \& \mathrm{D}$ intensity, sales-to-capital ratio, depreciation rate, market leverage, intangible-assets-to-capital ratio, and annual corporate bond return.

$B / M$ portfolios. - Firms with higher book-to-market ratios (i.e., value firms) have lower values of investment intensity, R\&D intensity, growth rate of R\&D intensity, sales-to-assets ratio, and intangible-assets-to-tangible-assets ratio but higher values of leverage ratio, compared to firms with lower book-to-market ratios (i.e., growth firms). It suggests that value firms invest less in both tangible and intangible assets, grow less, have lower productivity, accumulate less intangible assets relative to tangible assets, and borrow more, relative to growth firms. All of the above differences are statistically significant. We do not find significant cross-portfolio differences in the growth rates of investment intensity.

$I^{u} / K_{0}^{u}$ portfolios. - Firms with high $\mathrm{R} \& \mathrm{D}$ intensity tend to have higher values of investment intensity, sales-to-assets ratios, and intangible-assets-to-tangible-assets ratio but lower values of growth rate of $R \& D$ intensity and leverage ratio, compared to firms with low R\&D intensity. There is no clear pattern in the growth rate of investment intensity across the ten portfolios. The positive correlation between the physical investment intensity and R\&D intensity suggests that both the tangible and intangible investment decisions might be driven by the same economic forces.

$I^{u} / M E$ portfolios. - Different from the ten $I^{u} / K_{0}^{u}$ portfolios, the $I^{u} / M E$ portfolios do not show clear patterns in any firm characteristics except that the intangible-assets-to-tangible-assets ratio monotonically increases with the $I^{u} / M E$ ratio. Across the ten portfolios, higher $I^{u} / M E$ ratios are generally associated with lower R\&D-to-intangible-assets ratios, which explains why their relations with stock returns are in the opposite directions. 
To summarize, we observe significantly large spreads on intangible assets related characteristics across the $B / M$ portfolios, which underscores the important role of intangible assets in capturing the value premium. Moreover, we find that firms' investment decisions on intangible assets are positively correlated with those on tangible assets. Next, we turn to the structural estimation of the aforementioned four $q$-theory models.

\subsection{Parameter Estimates and Model Performance}

We estimate each of the four models, $Q m, Q u_{-} I S T C, Q u_{-} A C$, and $Q u$, using all three groups of testing portfolios: the $B / M, I^{u} / K_{0}^{u}$, and $I^{u} / M E$ portfolios. In addition to the parameter estimates, Table 3 also reports two measures of overall model performance: the average absolute pricing error (a.a.p.e.) across time and across portfolio, and the statistics of the $\chi^{2}$ test. The economic meaning of pricing errors is analogous to the alphas in the factor model regressions, representing the part of portfolio returns unexplained by the model. The $\chi^{2}$ test is the model overidentification test and constructed following Hansen (1982, Lemma 4.1.), with null hypothesis that the pricing errors are jointly zero.

We conduct two statistical tests to compare the model performance: the Wald test for the nested models: ${ }^{8} Q u, Q u_{-} I S T C$, and $Q u_{-} A C$, and the $\lambda$ test developed by Singleton (1985) for the non-nested models: $Q m$ and $Q u$. The null hypothesis of the Wald test is that the restrictions on a nested model are jointly satisfied. Applying the Wald test on the Qu_ISTC model and the $Q u$ model, we jointly test the null hypothesis: $b=0$ and $\psi=0$ (i.e., the AC effect is not present in the data). Similarly, the Wald test between the $Q u_{-} A C$ model and the $Q u$ model has the null hypothesis: $a_{2}=0$ (i.e., the ISTC effect is not present in the data). The $p$-values of the Wald test are reported in Table 3 Panels $\mathrm{A}, \mathrm{B}$, and $\mathrm{C}$ for the $B / M, I^{u} / K_{0}^{u}$, and $I^{u} / M E$ models, respectively.

The $Q m$ model and the $Q u$ model are not nested because even under the restrictions: $a_{2}=0$, $b=0$, and $\psi=0$, the production function in the $Q u$ model has intangible assets as an input, while the $Q m$ model does not. Therefore, we apply the $\lambda$ test developed by Singleton (1985) to compare the performance of the $Q m$ model and the $Q u$ model. For each set of testing portfolios, we calculate two statistics: $\lambda(Q m, Q u)$ and $\lambda(Q u, Q m) .{ }^{9}$ If the $Q m$ model is correctly specified, $\lambda(Q m, Q u)$ converges to a $\chi^{2}(1)$ distribution. On the other hand, if the $Q u$ model is correctly

\footnotetext{
${ }^{8}$ We use the Wald test instead of the L test used in Whited and $\mathrm{Wu}(2006)$ for the nested models. The L test requires the weighting matrix to satisfy the efficiency condition. Because we use identity matrix as the weighting matrix in the GMM estimation, our estimator does not satisfy the efficiency condition. Hayashi (2000, page 223) provides detailed discussions on the differences between the Wald test and the test statistics by the LR principle, to which the L test belongs.

${ }^{9}$ Singleton (1985) Section 3 provides details on how to construct the $\lambda$ statistic.
} 
specified, $\lambda(Q u, Q m)$ converges to a $\chi^{2}(1)$ distribution. The $p$-values of $\lambda(Q m, Q u)$ are reported under the columns of $Q m$ and the $p$-values of $\lambda(Q u, Q m)$ are reported under the columns of $Q u$ in Table 3 Panels $\mathrm{A}, \mathrm{B}$, and $\mathrm{C}$ for the $B / M, I^{u} / K_{0}^{u}$, and $I^{u} / M E$ portfolios, respectively.

$B / M$ portfolios. - The results from the $Q m$ model are largely consistent with those reported in LWZ. Compared to the $Q m$ model, the $Q u$ model captures the value premium much better and reduces the a.a.p.e. from $3.88 \%$ to $1.36 \%$ per annum. Figure 1 provides a visual representation of the model performance, plotting the predicted returns from each of the four models against the average realized returns for the ten $B / M$ portfolios. The scatters from the $Q u$ model look almost identical to those from the $Q u_{-} A C$ model, both of which gather more closely to the 45-degree line than the scatters from the $Q m$ model. The scatters from the $Q m$ model and the $Q u_{-} I S T C$ model look almost identical, indicating little improvement by adding the ISTC effect of intangible assets to the $Q m$ model. The $\chi^{2}$ test cannot reject the hypothesis that the pricing errors of the ten $B / M$ portfolios are jointly zero for none of the four $q$-theory models.

The non-nested test concludes that the $Q u$ model fits the cross-sectional stock returns of the $B / M$ portfolios significantly better than the $Q m$ model. The $p$-value of $\lambda(Q m, Q u)$ approaches zero, rejecting the null hypothesis that $Q m$ is the correct model specification at the $5 \%$ significance level. On the contrary, the $p$-value of $\lambda(Q u, Q m)$ is 0.98 , failing to reject the null hypothesis that $Q u$ is the correct model specification.

The Wald tests indicate that the AC effect of intangible assets is crucial for the $Q u$ model to capture the cross-sectional return spreads among the ten $B / M$ portfolios, while the ISTC effect is not, consistent with what we see from Figure 1. The Wald test between the $Q u_{-} I S T C$ and the $Q u$ model generates a $p$-value of 0.02 , rejecting the null hypothesis that $b=0$ and $\psi=0$ at the $5 \%$ significance level. On the contrary, the $p$-value of the Wald test between the $Q u_{-} A C$ model and the $Q u$ model approaches one, failing to reject the null hypothesis that $a_{2}=0$.

The $t$-statistics of the parameter estimates are generally insignificant except for the capital-toout ratio $\alpha$. We suspect that the low statistical power is due to the small size of our data sample. The $Q u$ model gives a lower estimate of $a$ than the $Q m$ model does, 1.21 vs. 43.59 , and a lower estimate of $\alpha, 0.40$ vs. 0.77 . Moreover, the $Q u$ model estimates $b$ to be 24.69 , much larger than its estimate of $a$. The curvature of the adjustment costs of intangible investment $\psi$ is 1.37 .

$I^{u} / K_{0}^{u}$ portfolios. - The $Q u$ model has an a.a.p.e. of 0.49 , much smaller compared to the a.a.p.e. of 1.93 from the $Q m$ model. Figure 2 visualizes the performances of the four $q$-theory models. The scatters from both the $Q u_{-} I S T C$ model and the $Q u_{-} A C$ model are more concentrated around the 45-degree line than those of the $Q m$ model, implying that both the ISTC and the AC effects improve the model performance. The scatters from the $Q u$ model line up along the 45-degree line 
almost perfectly and exhibit the best model fit. Again, the $\chi^{2}$ test cannot reject the hypothesis that the pricing errors of the ten $I^{u} / K_{0}^{u}$ portfolios are jointly zero for none of the four $q$-theory models.

The results of the non-nested test for the $I^{u} / K_{0}^{u}$ portfolios are identical to those for the $B / M$ portfolios. The $p$-value of $\lambda(Q m, Q u)$ approaches zero, rejecting the null hypothesis that $Q m$ is the correct model specification at the $5 \%$ significance level; the $p$-value of $\lambda(Q u, Q m)$ is 0.98 , failing to reject the null hypothesis that $Q u$ is the correct model specification. Therefore, the $Q u$ model fits the cross-sectional stock returns of the $I^{u} / K_{0}^{u}$ portfolios significantly better than the Qm model.

The Wald test between the $Q u_{-} I S T C$ model and the $Q u$ model and the Wald test between the $Q u_{-} A C$ model and the $Q u$ both have a $p$-value close to zero, indicating that both the ISTC effect and the $\mathrm{AC}$ effect are crucial to the improved model performance of the $Q u$ model, compared to the $Q m$ model.

The parameter estimates show similar patterns as what we see from the estimation of the $B / M$ portfolios. The estimates of $a$ and $\alpha$ from the $Q u$ model are 7.05 and 0.28 , respectively, smaller than the ones from the $Q m$ model, 13.31 and 0.35. The $Q u$ model again estimates a larger magnitude of $b, 27.76$, than its estimate of $a$. The curvature of adjustment costs $\psi$ for intangible investments is estimated to be 1.64 .

$I^{u} / M E$ portfolios. - The $Q u$ model has an a.a.p.e. of 0.78, much smaller than the a.a.p.e. of 3.19 from the $Q m$ model. The scatter plots in Figure 3 confirm that the $Q u$ model gives the best fit among all. Moreover, both the ISTC and AC effects are important to the improved model performance of $Q u$. Same as what we find with the other two sets of testing portfolios, the $\chi^{2}$ test cannot reject the hypothesis that the pricing errors of the ten $I^{u} / M E$ portfolios are jointly zero for none of the four $q$-theory models.

The Wald tests confirms what we learn from Figure 3. The $p$-value of $\lambda(Q m, Q u)$ is 0.05 , rejecting the null hypothesis that $Q m$ is the correct model specification at the $5 \%$ significance level; the $p$-value of $\lambda(Q u, Q m)$ approaches one, failing to reject the null hypothesis that $Q u$ is the correct model specification. Therefore, the $Q u$ model matches the return spreads of the $I^{u} / M E$ portfolios significantly better than the $Q m$ model. The Wald test between the $Q u$ model and the $Q u_{-} I S T C$ and the one between the $Q u$ and the $Q u_{-} A C$ model both have a $p$-value of zero, indicating that both the ISTC and the AC effects are crucial to the improved performance.

Consistent with what we find with the $B / M$ portfolios and the $I^{u} / K_{0}^{u}$ portfolios, the $Q u$ model always gives smaller estimates of $a$ and $\alpha$ than the $Q m$ model, 2.71 vs. 69.34 for $a$ and 0.14 vs. 1.00 for $\alpha$. The magnitude of $b$ estimated from the $Q u$ model is 56.20, much larger than that of 
a. The curvature $\psi$ is estimated to be 0.59 .

In summary, there are several patterns that arise after comparing different models. First, all four $q$-theory models capture the cross-sectional stock returns pretty well. The $\chi^{2}$ tests fail to reject that the pricing errors are jointly zero for neither model, using all three sets of testing portfolios. Second, the $\lambda$ tests show that adding intangible assets to the conventional $q$-theory model significantly improves the model performance across all three sets of testing portfolios. Moreover, both the ISTC and AC effects of intangible assets are crucial to the improved model performance. Third, the $Q u$ model estimates a smaller value of $a$ than the $Q m$ model and the magnitude of $b$ is larger than that of $a$, across all three sets of testing portfolios. Next, we calculate the average adjustment costs for both tangible and intangible investments based on the estimates of $a, b$, and $\psi$.

\subsection{Comparative statics analysis}

In this section, we explore how important the cross-sectional variation of a specific characteristic, particularly the ones related to intangible assets, is for the model to match cross-sectional return spreads. We reconstruct the predicted stock returns using the same parameter estimates from the $Q u$ model, but make one change: for a given characteristic at a given year, we use its cross-sectional average at that year in equation (6) while keeping other characteristics unchanged. We then calculate the a.a.p.e. based on the reconstructed stock returns and measure the degree of performance deterioration based on the increase in a.a.p.e. relative to the corresponding one reported in Table 3 . The more crucial a certain characteristic is to matching the cross-sectional return spreads, the greater the increase in a.a.p.e. we observe. Table 4 reports the results of our comparative statics analysis on five characteristics: the tangible investment ratio $I^{m} / K^{m}$, the intangible investment ratio $I^{u} / K^{u}$, the intangible-to-tangible-assets ratio $K^{u} / K$, the sales-to-assets ratio $Y / K^{m}$ and the leverage $w$, for all three sets of testing portfolios.

For the ten $B / M$ portfolios, the most important characteristics are $I^{u} / K^{u}$ and $K^{u} / K^{m}$. Taking away the cross-sectional variations of $I^{u} / K^{u}$ and $K^{u} / K^{m}$ increases the a.a.p.e. of the $Q u$ model from $1.36 \%$ to $6.15 \%$ and $6.28 \%$, respectively. This result confirms our previous estimation analysis that adding intangible assets to the conventional $q$-theory is important in capturing the value premium. Leverage $w$ is the third important component. Without the variation in leverage, the a.a.p.e. increases to $3.31 \% . Y / K^{m}$ and $I^{m} / K^{m}$ are less important compared to the other three characteristics, which explains why the conventional $q$-theory does a poor job in matching the value premium.

For the $I^{u} / K_{0}^{u}$ portfolios, the most important characteristic is $K^{u} / K^{m}$, which leads to an 
increase in a.a.p.e. from $0.49 \%$ to $2.97 \% . I^{u} / K^{u}, I^{m} / K^{m}$, and $w$ are equally important, resulting in an increase of a.a.p.e. from $0.49 \%$ to $1.88 \%, 2.07 \%$, and $1.83 \%$, respectively. $Y / K^{m}$ is the least important one, raising the a.a.p.e. to $1.58 \%$.

For the $I^{u} / M E$ portfolios, the most crucial characteristic is the leverage $w$. Without the variation in leverage, the a.a.p.e. of the $Q u$ model increases from $0.78 \%$ to $5.85 \%$. $Y / K^{m}, K^{u} / K^{m}$, and $I^{u} / K^{u}$ have similar importance, raising the a.a.p.e. to $3.60 \%, 3.25 \%$, and $3.24 \%$, respectively. $I^{m} / K^{m}$ is the least important one, raising the a.a.p.e. to $1.55 \%$. The fact that leverage $w$, instead of the characteristics related to intangible assets, is the most important characteristic in matching the return spreads across the $I^{u} / M E$ portfolios is consistent with our previous conjecture that using $I^{u} / M E$ as the sorting variable may capture the leverage effect, in addition to the effect from R\&D investments.

\subsection{Magnitude of adjustment costs}

In this subsection, we compare the magnitudes of adjustment costs of tangible and intangible investments implied from the structural estimations. The adjustment-costs-to-investments ratio $(A C / I)$ is commonly used as a measure of the magnitude of adjustment costs in the literature. Given the parameter estimates and the investment ratios, the average $A C / I$ ratio across all testing portfolios can be calculated as

$$
\frac{A C^{m}}{I^{m}}=\frac{1}{10} \sum_{i=1}^{10} \frac{\hat{a}}{2} \overline{\left(\frac{I_{i}^{m}}{K_{i}^{m}}\right)} \text { and } \frac{A C^{u}}{I^{u}}=\frac{1}{10} \sum_{i=1}^{10} \frac{\hat{b}}{2} \overline{\left(\frac{I_{i}^{u}}{K_{i}^{u}}\right)^{\psi-1}}
$$

for tangible and investments, respectively. Here $i$ stands for portfolio $i, \hat{a}$ and $\hat{b}$ are the estimated values for $a$ and $b$, and the variables with an overline are the time-series average of the corresponding variables. Table 5 reports both the $A C^{m} / I^{m}$ ratios and the $A C^{u} / I^{u}$ ratios implied by all three sets of testing portfolios. For the $A C^{m} / I^{m}$ ratios, we report the values implied by both the $Q m$ model and the $Q u$ model.

Based on the estimates from the $Q u$ model, the $A C^{m} / I^{m}$ ratios are $6.43 \%, 39.05 \%$, and $14.17 \%$ for the $B / M$, the $I^{u} / K_{0}^{u}$, and the $I^{u} / M E$ portfolios, respectively, averaging to $19.88 \%$. For the $Q m$ model, those numbers are $232 \%, 73.7 \%$, and $363 \%$, averaging to $223 \%$. The estimates of the $A C^{m} / I^{m}$ ratio from Summers (1981), Litchenberg (1988), and Cooper and Haltiwanger (2006) are similar in magnitude, being $22.1 \%, 20 \%$, and $33.09 \%$, respectively. ${ }^{10}$ The estimate from Hall

\footnotetext{
${ }^{10}$ Cooper and Haltiwanger (2006) consider both the fixed and the quadratic parts of the adjustment costs. With only the quadratic adjustment costs, the $A C^{m} / I^{m}$ ratio is $2.78 \%$.
} 
(2004) is even smaller and close to zero. Therefore, the IAA $q$-theory gives a more reasonable estimate of adjustment costs than the conventional $q$-theory.

For intangible investments, the $A C^{u} / I^{u}$ ratios are $839 \%, 589 \%$, and $5,708 \%$ for the $B / M$ portfolios, the $I^{u} / K_{0}^{u}$ portfolios, and the $I^{u} / M E$ portfolios, respectively, averaging to $2,379 \%$. Across all testing portfolios, the $A C^{u} / I^{u}$ ratio is consistently larger than the $A C^{m} / I^{m}$ ratio, implying that it is more costly to rapidly accumulate intangible assets than tangible assets. This finding confirms the conventional wisdom that the comparative advantage due to intangible assets is easier to sustain than the one due to tangible assets. It is hence important for firms to consistently invest in intangible assets.

Even though it is consistent with the economic intuition and the aforementioned empirical facts to have a larger magnitude of adjustment costs for intangible investments than that for tangible investments, our model implied $A C^{u} / I^{u}$ ratios seem fairly large. We suspect the following reasons that could lead to over-estimation of the adjustment costs of intangible investments: (1) the assumption that R\&D expenditures older than 5 years do not contribute to the current intangible assets; (2) the omission of other types of intangible assets, especially human capital, which presumably can be quite large in magnitude; (3) the success rate of R\&D is assumed to be one. The first two assumptions lead to under-estimation of the level of intangible assets, which gives a higher R\&D-to-intangible-assets ratio and hence a higher $A C^{u} / I^{u}$ ratio. The third assumption attributes failed R\&D costs to adjustment costs and makes the latter overestimated.

In summary, the IAA $q$-theory gives a more reasonable estimate of adjustment costs for tangible investments than the conventional $q$-theory does. The $A C^{m} / I^{m}$ ratio from the $Q u$ model is within the range of what previous studies find using different methodologies and data samples. Moreover, the $A C^{u} / I^{u}$ ratio is estimated to be larger than the $A C^{m} / I^{m}$ ratio.

Notice that the estimated model parameters and hence the average adjustment costs vary across different sets of testing portfolios, even though the portfolios are constructed using the same set of firms. In theory, every firm is different and the model parameters should vary across each individual firm. When grouping firms into portfolios and estimate the parameters at the portfolio level, ${ }^{11}$ we treat each portfolio as a "representative" for firms in that portfolio and estimating the model parameters that best describe the behaviors of the ten representative firms. With different sets of testing portfolios, we group firms differently and end up with representative firms with different characteristics, as shown in Table 2. Therefore, the parameter estimates based on those representative firms inevitably vary across the three sets of testing portfolios.

\footnotetext{
${ }^{11}$ Using the current methodology, we are not be able to estimate the parameters at the firm level because many firms do not have long enough time series of data. Moreover, one motivation of the paper is to investigate the ability of the IAA $q$-theory in capturing the value premium, which is a portfolio-level phenomena.
} 


\section{Conclusion}

Intangible assets have become increasingly important for a firm's survival and prosperity since the 1980s. The literature has emphasized two important features of intangible assets: the adjustment costs of intangible investments and the investment-specific-technologic-change. In this paper, we examine the impacts of intangible assets on asset returns and the importance of these two features based on structural estimations of four $q$-theory models. Moreover, we quantify the magnitude of the adjustment costs of both tangible and intangible investments.

The estimation shows that incorporating intangible investments into the $q$-theory framework is critical for the model to explain cross-sectional stock returns and generate a reasonable estimate of the adjustment costs of tangible investments. It is more costly to accumulate intangible assets than tangible assets. Finally, we document that the R\&D intensity, when measured as the ratio of $\mathrm{R} \& \mathrm{D}$ investments to intangible assets, is negatively related to stock returns, which resembles the relation between stock returns and physical investment intensity, measured as the $I / K$ ratio. This finding is opposite to the perception in the literature that the $R \& D$ intensity is positively related to stock returns. We argue that the R\&D-to-market-equity ratio is not a good proxy of R\&D intensity for the purpose of investigating the impact of $R \& D$ investments on stock returns, because it likely reflects the value effect and the leverage effect.

\section{References}

Albuquerque, R., Shroth, E., 2010. Quantifying private benefits of control from a structural model of block trades. Journal of Financial Economics 96 (1), 33-55.

Belo, Frederico, Xiaoji Lin, and Maria Ana Vitorino, 2012, Brand Capital, Firm Value and Asset Returns, University of Minnesota, working paper.

Chan, L., Lakonishok, J., Sougiannis, T., 2001. The stock market valuation of research and development expenditures. Journal of Finance 56 (6), 2431-2456.

Cochrane, J. H., 1996. A cross-sectional test of an investment-based asset pricing model. Journal of Political Economy 104, 572-621.

Cooper, R. W., Haltiwanger, J. C., 2006. On the nature of capital adjustment costs. Review of Economic Studies 73 (2), 611-633.

Fama, E. F., French, K. R., 1993. Common risk factors in the returns on stocks and bonds. Journal of Financial Economics 33, 3-56. 
Greenwood, J., Hercowitz, Z., Krusell, P., 1997. Long-run implications of investment-specific technological change. American Economic Review 87 (3), 342-362.

Hansen, L. P., 1982. Large sample properties of generalized method of moments estimators. Econometrica 40 (4), 1029-54.

Hayashi, F., 2000. Econometrics, NJ, Princeton University Press.

Hirshleifer, David, Po-Hsuan Hsu, and Dongmei Li, 2011, Innovative efficiency and stock returns, working paper.

Hennessy, C., Whited, T. M., 2007. How costly is external financing? Evidence from a structural estimation. Journal of Finance 60, 1129-1165.

Hsu, Po-Hsuan, 2009, Technological innovations and aggregate risk premiums, Journal of Financial Economics 94 (2), 264-279.

Huffman, G. W., 2007. Endogenous growth through investment-specific technological change. Review of Economic Dynamics 10 (4), 615-645.

Knott, A. M., Bryce, D. J., Posen, H. E., 2003. On the strategic accumulation of intangible assets. Organization Science 14 (2), 192-207.

Lev, B., 2001. Intangibles, management, measurement and reporting, Brooking Institution Press.

Lev, B., Sougiannis, T., 1996. The capitalization, amortization and value-relevance of R\&D. Journal of Accounting and Economics 21 (1), 107-138.

Li, D., 2007. Financial Constraints, R\&D Investment, and Stock Return. Unpublished working paper. University of California San Diego.

Lin, Xiaoji, 2012, Endogenous Technological Progress and the Cross Section of Stock Returns, Journal of Financial Economics, 103 (2): 411-428.

Litchenberg, F. R., 1988. Estimation of the internal adjustment costs model using longitudinal establishment data. The Review of Economics and Statistics 70 (3), 421-430.

Liu, L. X., Whited, T. M., Zhang, L., 2009. Investment-based expected stock returns. Journal of Political Economy 117 (6), 1105-1139. 
Singleton, K., 1985. Testing specifications of economic agents' intertemporal optimum problems in the presence of alternative models. Journal of Econometrics 30 (2), 391-413.

Summers, L. H., 1981. Taxation and corporate investment: a q-theory approach, Brookings Papers on Economic Activity 1, 67-127.

Titman, S., Wei, J. K., Xie, F., 2004. Capital investments and stock returns. Journal of Financial and Quantitative Analysis 39, 677-700.

Vitorino, Maria Ana, 2012, Understanding the Effect of Advertising on Stock Returns and Firm Value: Theory and Evidence from a Structural Model, University of Pennsylvania, working paper.

Whited, T. M., Wu, G., 2006. Financial constraints risk. Review of Financial Studies 19, 531-559. 


\section{Proof of Proposition 1}

Shareholders maximize the following objective function

$$
P_{t} \equiv P\left(K_{t}^{m}, K_{t}^{u}, B_{t}, X_{t}\right)=\max _{\left\{I_{t}^{m}, I_{t}^{u}, K_{t+1}^{m}, K_{t+1}^{u}, L_{t}\right\}}\left\{D_{t}^{S}+\mathbb{E}_{t}\left[M_{t+1} \mathbb{I}_{t+1} P_{t+1}\right]\right\}
$$

subject to

$$
\begin{aligned}
q_{t}^{u}: & K_{t+1}^{u}=\left(1-\delta_{u}\right) K_{t}^{u}+I_{t}^{u} \\
q_{t}^{m}: & K_{t+1}^{m}=\left(1-\delta_{m}\right) K_{t}^{m}+\Theta\left(I_{t}^{m}, K_{t}^{u}\right) .
\end{aligned}
$$

We prove Proposition 1 in three steps.

Step 1: We show that ex-dividend firm value $V_{t}$ is given by

$$
V_{t} \equiv P_{t}-D_{t}^{S}+B_{t+1}=q_{t}^{u} K_{t+1}^{u}+q_{t}^{m} K_{t+1}^{m}
$$

The first order conditions of shareholder's maximization problem are

$$
\begin{aligned}
I_{t}^{u}: & \Theta_{I, t} q_{t}^{u}=\left(1-\tau_{t}\right)\left(1+\Phi_{I, t}^{u}\right) \\
I_{t}^{m}: & q_{t}^{m}=1+\left(1-\tau_{t}\right) \Phi_{I, t}^{m} \\
L_{t}: & \varpi_{t}=Y_{L, t} \\
K_{t+1}^{u}: & q_{t}^{u}=\mathbb{E}_{t}\left[M_{t+1} \mathbb{I}_{t+1} V_{K^{u}, t+1}\right] \\
K_{t+1}^{m}: & q_{t}^{m}=\mathbb{E}_{t}\left[M_{t+1} \mathbb{I}_{t+1} V_{K^{m}, t+1}\right] \\
B_{t+1}: & 1=\mathbb{E}_{t}\left[M_{t+1} \mathbb{I}_{t+1}\left[r_{t+1}^{B}-\left(r_{t+1}^{B}-1\right) \tau_{t+1}\right]\right],
\end{aligned}
$$

where $V_{K^{u}, t+1}$ is the derivative of the value function w.r.t. $K_{t+1}^{u}$ and $V_{K^{m}, t+1}$ and $Y_{L, t}$ are defined similarly.

It's straightforward to show that the adjustment function, production function of new tangible assets, and the production function satisfy constant-return-to-scale. Therefore, from the firs-order conditions, we can write the right hand side of equation (15) as

$$
q_{t}^{u} K_{t+1}^{u}+q_{t}^{m} K_{t+1}^{m}=\mathbb{E}_{t}\left[M_{t+1} \mathbb{I}_{t+1}\left(V_{K^{m}, t+1} K_{t+1}^{m}+V_{K^{u}, t+1} K_{t+1}^{u}\right)\right]
$$


Define a function $\Omega_{t+1}$ as

$$
\begin{aligned}
\Omega_{t+1}= & V_{K^{m}, t+1} K_{t+1}^{m}+V_{K^{u}, t+1} K_{t+1}^{u} \\
= & {\left[\left(1-\tau_{t}\right)\left(Y_{K^{m}, t}-\Phi_{K, t+1}^{m}\right)+\tau_{t} \delta_{m}+q_{t}^{m}\left(1-\delta_{m}\right)\right] K_{t+1}^{m} } \\
& +\left[\left(1-\tau_{t}\right) Y_{K^{u}, t}+q_{t}^{u}\left(1-\delta_{u}\right)+q_{t}^{u} \Theta_{K, t}\right] K_{t+1}^{u} .
\end{aligned}
$$

Substituting the first-order conditions into the above equation and using the constant-return-toscale property of the production function and the adjustment cost function, we can show

$$
\Omega_{t+1}=D_{t+1}+q_{t+1}^{m} K_{t+2}^{m}+q_{t+1}^{u} K_{t+2}^{u}
$$

Therefore, the right hand side of equation (15) can be written as

$$
\begin{aligned}
q_{t}^{m} K_{t+1}^{m}+q_{t}^{u} K_{t+1}^{u} & =\mathbb{E}_{t}\left[M_{t+1} \mathbb{I}_{t+1}\left[D_{t+1}+q_{t+1}^{m} K_{t+2}^{m}+q_{t+1}^{u} K_{t+2}^{u}\right]\right] \\
& =\mathbb{E}_{t}\left[\sum_{s=0}^{\infty} M_{t+s} \mathbb{I}_{t+s} D_{t+s}\right]
\end{aligned}
$$

Firm value $V_{t}$ is the sum of ex-dividend equity value and debt value, that is,

$$
\begin{aligned}
V_{t} & =P_{t}-D_{t}^{S}+B_{t+1} \\
& =\mathbb{E}_{t}\left[M_{t+1} \mathbb{I}_{t+1}\left\{D_{t+1}^{S}+P_{t+1}+\left[r_{t+1}^{B}-r_{t+1}^{B}\left(1-\tau_{t+1}\right)\right] B_{t+1}\right\}\right]
\end{aligned}
$$

where the second equation is derived from the first order condition on the optimal debt issuance

$$
B_{t+1}=\mathbb{E}_{t}\left[M_{t+1} \mathbb{I}_{t+1}\left[r_{t+1}^{B}-r_{t+1}^{B}\left(1-\tau_{t+1}\right)\right] B_{t+1}\right]
$$

It's straightforward to show that

$$
D_{t+1}^{S}+\left[r_{t+1}^{B}-r_{t+1}^{B}\left(1-\tau_{t+1}\right)\right] B_{t+1}=D_{t+1}+B_{t+2} .
$$

Therefore, we have

$$
V_{t}=\mathbb{E}_{t}\left[M_{t+1} \mathbb{I}_{t+1}\left(D_{t+1}+B_{t+2}+P_{t+1}\right)\right]=\mathbb{E}_{t}\left[M_{t+1} \mathbb{I}_{t+1}\left(D_{t+1}+V_{t+1}\right)\right]
$$


Iterating the above equation, we get

$$
V_{t}=\mathbb{E}_{t}\left[\sum_{s=0}^{\infty} M_{t+s} \mathbb{I}_{t+s} D_{t+s}\right]
$$

which, combined with equation (19), implies that

$$
V_{t}=q_{t}^{m} K_{t+1}^{m}+q_{t}^{u} K_{t+1}^{u}
$$

Step 2: We show that firm's investment return, defined as

$$
r_{t+1}^{I}=\frac{D_{t+1}+q_{t+1}^{m} K_{t+2}^{m}+q_{t+1}^{u} K_{t+2}^{u}}{q_{t}^{m} K_{t+1}^{m}+q_{t}^{u} K_{t+1}^{u}}
$$

satisfies the following equations:

$$
\begin{aligned}
\mathbb{E}_{t}\left[M_{t+1} \mathbb{I}_{t+1} r_{t+1}^{I}\right] & =1 \\
r_{t+1}^{I} & =\varpi_{t} r_{t+1}^{S}+\left(1-\varpi_{t}\right) r_{t+1}^{B a}
\end{aligned}
$$

Equation (20) is straightforward to prove. Dividing the right-hand side of equation

$$
q_{t}^{m} K_{t+1}^{m}+q_{t}^{u} K_{t+1}^{u}=\mathbb{E}_{t}\left[M_{t+1} \mathbb{I}_{t+1}\left(D_{t+1}+q_{t+1}^{m} K_{t+2}^{m}+q_{t+1}^{u} K_{t+2}^{u}\right)\right] .
$$

by its left-hand side, we get

$$
1=\mathbb{E}_{t}\left[M_{t+1} \mathbb{I}_{t+1}\left(\frac{D_{t+1}+q_{t+1}^{m} K_{t+2}^{m}+q_{t+1}^{u} K_{t+2}^{u}}{q_{t}^{m} K_{t+1}^{m}+q_{t}^{u} K_{t+1}^{u}}\right)\right]=\mathbb{E}_{t}\left[M_{t+1} \mathbb{I}_{t+1} r_{t+1}^{I}\right]
$$

To prove equation (21), we first show that

$$
\begin{aligned}
\frac{D_{t+1}+q_{t+1}^{m} K_{t+2}^{m}+q_{t+1}^{u} K_{t+2}^{u}}{q_{t}^{m} K_{t+1}^{m}+q_{t}^{u} K_{t+1}^{u}} & =\frac{D_{t+1}^{S}+\left[r_{t+1}^{B}-\tau_{t+1}\left(r_{t+1}^{B}-1\right)\right] B_{t+1}-B_{t+2}+V_{t+1}}{V_{t}} \\
& =\frac{D_{t+1}^{S}+r_{t+1}^{B a} B_{t+1}-B_{t+2}+P_{t+1}-D_{t+1}^{S}+B_{t+2}}{V_{t}} \\
& =\frac{P_{t+1}+r_{t+1}^{B a} B_{t+1}}{V_{t}} \\
& =\left(1-w_{t}\right) r_{t+1}^{S}+w_{t} r_{t+1}^{B a} .
\end{aligned}
$$


From firm's optimal choice of capital and labor, we have

$$
Y_{t}-\varpi_{t} L_{t}^{*}=\gamma Y_{t} .
$$

Substitute equations (16), (17), (22), and the accumulation rules of both tangible and intangible assets into equation (21) and divide both the denominator and the numerator by $K_{t+1}^{m}$. It's straightforward to get equation (6). Therefore, we conclude that

$$
r_{t+1}^{I}=\left(1-w_{t}\right) r_{t+1}^{S}+w_{t} r_{t+1}^{B a} .
$$

Step 3: Since $q_{t}^{m}$ is the shadow price of one unit of tangible assets at time $t$, the market value of firm's tangible assets is $q_{t}^{m} K_{t+1}^{m}$. Similarly, the market value of firm's intangible assets is $q_{t}^{m} K_{t+1}^{m}$. From Lemma ??, we know that $V_{t}=q_{t}^{m} K_{t+1}^{m}+q_{t}^{m} K_{t+1}^{m}$. Hence, the weights $w_{t}^{m}$ and $w_{t}^{m}$ add up to 1. From the FOCs of the shareholder's value maximization, we have

$$
\begin{aligned}
q_{t}^{m} & =1+\left(1-\tau_{t}\right) \Phi_{I, t}^{m} \\
q_{t}^{u} & =\frac{\left(1+\tau_{t}\right)\left(1+\Phi_{I, t}^{u}\right)}{\Theta_{I, t}}
\end{aligned}
$$

Plug in the above equations and it is straightforward to show that

$$
r_{t+1}^{I}=w_{t}^{m} r_{t+1}^{I, m}+w_{t}^{u} r_{t+1}^{I, u} .
$$

\section{Definitions and Sources of Data Items}

We list the Compustat item names for the variables used in the data construction.

Book Equity: Common Equity (CEQ) + Balance Sheet Deferred Tax (TXDB)

Total Asset: Total Asset (AT)

Market Value of Debt: Long-Term Debt (DLTT) + Short-Term Debt (DLC)

Market Value of Asset: Long-Term Debt (DLTT) + Short-Term Debt (DTC) + Share Outstanding $(\mathrm{CSHO}) \times$ Stock Price - Annual Fiscal Year $\left(\mathrm{PRCC} \_\right.$F $)$ 
Capital Stock: Gross Property, Plant, and Equipment (PPEGT)

R\&D Expenditure: Research and Development Expense (XRD)

Physical Investment: Capital Expenditure (CAPX) - Sales of Property, Plant, and Equipment (SPPE)

Output: Sales (SALE)

Depreciation Rate of Tangible Assets: mean of the Depreciation (DP) to Gross Property, Plant, and Equipment (PPEGT) ratios over the entire time series

Market Leverage: Book Value of Debt / Market Equity 


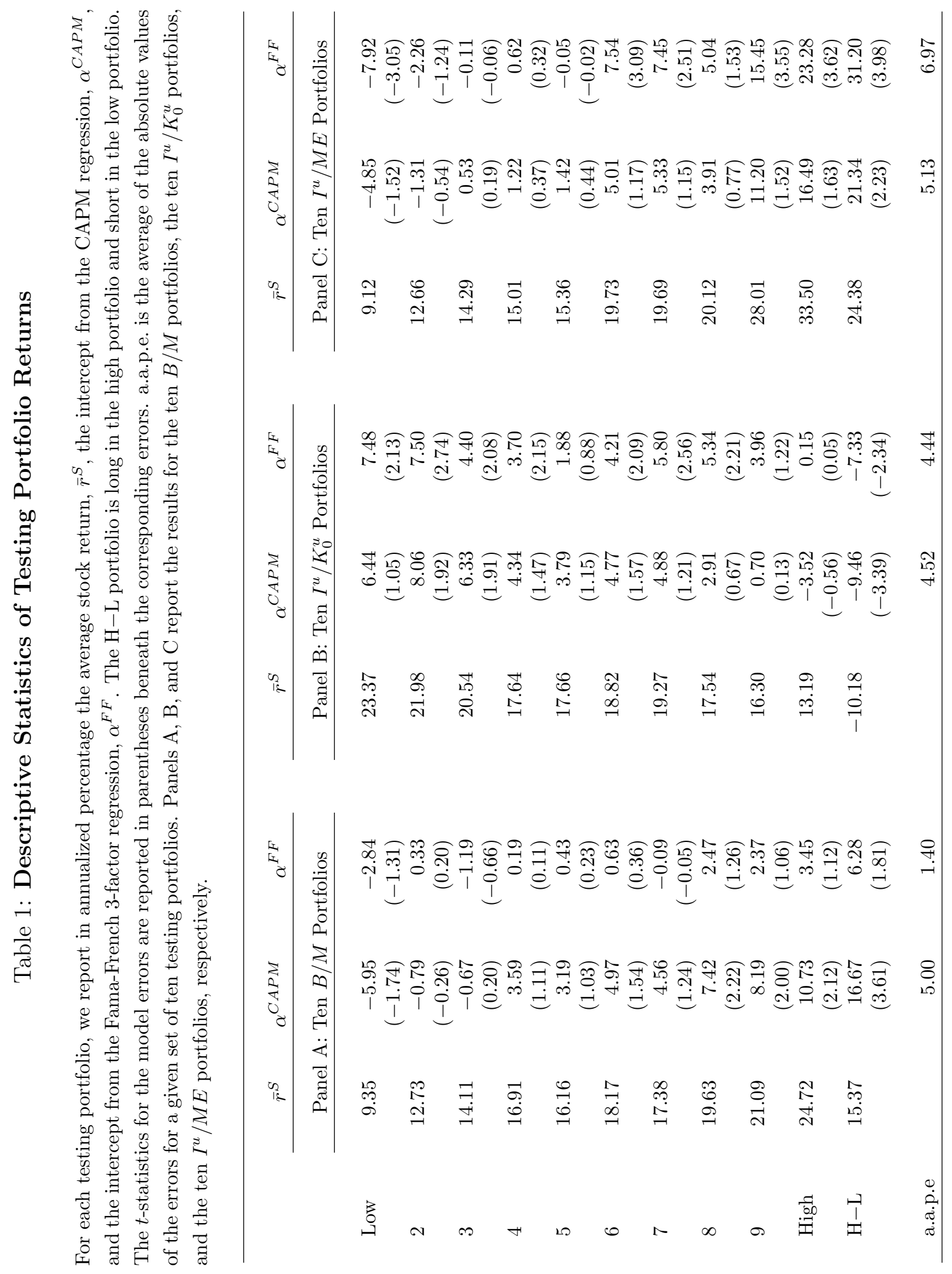




\section{Table 2: Summary Statistics of Portfolio Characteristics}

This table reports the averages of future investment-to-capital, $I_{t+1}^{m} / K_{t+1}^{m}$, current investment-to-capital, $I_{t}^{m} / K_{t}^{m}$, investment growth, $\left(I_{t+1}^{m} / K_{t+1}^{m}\right) /\left(I_{t}^{m} / K_{t}^{m}\right)$, future R\&D-to-intangible-assets, $I_{t+1}^{u} / K_{0, t+1}^{u}$, R\&D-to-intangibleassets, $I_{t}^{u} / K_{0, t}^{u}$, R\&D growth, $\left(I_{t+1}^{u} / K_{0, t+1}^{u}\right) /\left(I_{t}^{u} / K_{0, t}^{u}\right)$, sales-to-capital, $Y_{t+1} / K_{t+1}^{m}$, the depreciation rate, $\delta_{t+1}$, market leverage, $w_{t}$, intangible-assets-to-capital, $K_{0, t+1}^{u} / K_{t+1}^{m}$, and annual corporate bond returns in percentage, $r_{t+1}^{B}$, for each testing portfolio. The row $\mathrm{H}-\mathrm{L}$ reports the average differences between high and low portfolios, beneath which are their corresponding $t$-statistics reported in parentheses. Panels $\mathrm{A}, \mathrm{B}$, and $\mathrm{C}$ report the results for the ten $B / M$ portfolios, the ten $I^{u} / K_{0}^{u}$ portfolios, and the ten $I^{u} / M E$ portfolios, respectively.

\begin{tabular}{|c|c|c|c|c|c|c|c|c|c|c|c|}
\hline & $\frac{I_{t+1}^{m}}{K_{t+1}^{m}}$ & $\frac{I_{t}^{m}}{K_{t}^{m}}$ & $\frac{I_{t+1}^{m} / K_{t+1}^{m}}{I_{t}^{m} / K_{t}^{m}}$ & $\frac{I_{t+1}^{u}}{K_{0, t+1}^{u}}$ & $\frac{I_{t}^{u}}{K_{0, t}^{u}}$ & $\frac{I_{t+1}^{u} / K_{t+1}^{u}}{I_{t}^{u} / K_{t}^{u}}$ & $\frac{Y_{t+1}}{K_{t+1}^{m}}$ & $\delta_{t+1}$ & $w_{t}$ & $\frac{K_{0, t+1}^{u}}{K_{t+1}^{m}}$ & $r_{t+1}^{B}$ \\
\hline & \multicolumn{11}{|c|}{ Panel A: Ten $B / M$ portfolios } \\
\hline Low & 0.15 & 0.16 & 0.97 & 0.43 & 0.42 & 1.01 & 2.00 & 0.09 & 0.10 & 0.25 & 10.99 \\
\hline 2 & 0.12 & 0.13 & 0.98 & 0.38 & 0.38 & 1.00 & 1.76 & 0.09 & 0.18 & 0.16 & 10.63 \\
\hline 3 & 0.11 & 0.12 & 0.98 & 0.36 & 0.37 & 1.00 & 1.75 & 0.08 & 0.26 & 0.12 & 10.55 \\
\hline 4 & 0.11 & 0.12 & 0.97 & 0.36 & 0.36 & 1.01 & 1.58 & 0.08 & 0.25 & 0.11 & 10.65 \\
\hline 5 & 0.11 & 0.11 & 1.01 & 0.34 & 0.35 & 0.99 & 1.56 & 0.08 & 0.26 & 0.10 & 10.75 \\
\hline 6 & 0.10 & 0.10 & 1.01 & 0.34 & 0.34 & 0.99 & 1.39 & 0.08 & 0.31 & 0.07 & 11.02 \\
\hline 7 & 0.10 & 0.10 & 0.95 & 0.33 & 0.34 & 0.97 & 1.34 & 0.07 & 0.34 & 0.07 & 11.12 \\
\hline 8 & 0.09 & 0.09 & 1.01 & 0.34 & 0.33 & 1.02 & 1.21 & 0.07 & 0.42 & 0.05 & 11.14 \\
\hline 9 & 0.09 & 0.10 & 0.97 & 0.33 & 0.34 & 0.98 & 1.29 & 0.08 & 0.48 & 0.06 & 11.24 \\
\hline High & 0.09 & 0.09 & 0.98 & 0.31 & 0.34 & 0.95 & 1.44 & 0.08 & 0.48 & 0.06 & 11.52 \\
\hline \multirow[t]{2}{*}{$\mathrm{H}-\mathrm{L}$} & $\begin{array}{l}-0.06 \\
(-7.41)\end{array}$ & $\begin{array}{c}-0.07 \\
(-6.67)\end{array}$ & $\begin{array}{c}0.01 \\
(0.37)\end{array}$ & $\begin{array}{c}-0.11 \\
(-13.48)\end{array}$ & $\begin{array}{l}-0.08 \\
(-6.96)\end{array}$ & $\begin{array}{c}-0.07 \\
(-2.44)\end{array}$ & $\begin{array}{c}-0.57 \\
(-7.32)\end{array}$ & $\begin{array}{c}-0.01 \\
(-1.83)\end{array}$ & $\begin{array}{c}0.37 \\
(12.49)\end{array}$ & $\begin{array}{c}-0.18 \\
(-11.48)\end{array}$ & $\begin{array}{c}0.53 \\
(0.88)\end{array}$ \\
\hline & \multicolumn{11}{|c|}{ Panel B: Ten $I^{u} / K_{0}^{u}$ portfolios } \\
\hline Low & 0.09 & 0.09 & 1.09 & 0.23 & 0.19 & 1.20 & 1.61 & 0.07 & 0.29 & 0.16 & 11.62 \\
\hline 2 & 0.08 & 0.08 & 1.03 & 0.29 & 0.26 & 1.12 & 1.45 & 0.07 & 0.32 & 0.11 & 11.70 \\
\hline 3 & 0.09 & 0.09 & 1.04 & 0.31 & 0.31 & 1.03 & 1.51 & 0.07 & 0.29 & 0.14 & 11.34 \\
\hline 4 & 0.09 & 0.09 & 0.99 & 0.33 & 0.33 & 1.00 & 1.61 & 0.08 & 0.26 & 0.15 & 11.04 \\
\hline 5 & 0.10 & 0.11 & 0.98 & 0.35 & 0.35 & 1.00 & 1.61 & 0.08 & 0.26 & 0.16 & 10.72 \\
\hline 6 & 0.12 & 0.12 & 0.95 & 0.38 & 0.38 & 0.99 & 1.86 & 0.09 & 0.26 & 0.25 & 10.67 \\
\hline 7 & 0.12 & 0.13 & 0.98 & 0.40 & 0.41 & 0.98 & 1.99 & 0.09 & 0.15 & 0.26 & 10.78 \\
\hline 8 & 0.13 & 0.14 & 1.02 & 0.43 & 0.46 & 0.95 & 1.95 & 0.10 & 0.15 & 0.28 & 10.90 \\
\hline 9 & 0.13 & 0.15 & 0.93 & 0.45 & 0.49 & 0.92 & 2.34 & 0.11 & 0.16 & 0.29 & 11.27 \\
\hline High & 0.16 & 0.16 & 0.97 & 0.50 & 0.62 & 0.83 & 2.76 & 0.12 & 0.15 & 0.30 & 11.30 \\
\hline \multirow[t]{2}{*}{$\mathrm{H}-\mathrm{L}$} & $\begin{array}{c}0.07 \\
(5.91)\end{array}$ & $\begin{array}{c}0.08 \\
(7.15)\end{array}$ & $\begin{array}{c}-0.12 \\
(-1.36)\end{array}$ & $\begin{array}{c}0.27 \\
(16.60)\end{array}$ & $\begin{array}{c}0.43 \\
(14.68)\end{array}$ & $\begin{array}{c}-0.37 \\
(-9.30)\end{array}$ & $\begin{array}{c}1.15 \\
(3.80)\end{array}$ & $\begin{array}{c}0.04 \\
(5.92)\end{array}$ & $\begin{array}{c}-0.14 \\
(-10.12)\end{array}$ & $\begin{array}{c}0.14 \\
(3.87)\end{array}$ & $\begin{array}{c}-0.32 \\
(-1.41)\end{array}$ \\
\hline & \multicolumn{11}{|c|}{ Panel C: Ten $I^{u} / M E$ portfolios } \\
\hline Low & 0.09 & 0.10 & 0.97 & 0.39 & 0.39 & 1.02 & 1.44 & 0.07 & 0.22 & 0.02 & 10.64 \\
\hline 2 & 0.09 & 0.10 & 0.98 & 0.39 & 0.39 & 1.01 & 1.37 & 0.07 & 0.23 & 0.07 & 10.55 \\
\hline 3 & 0.10 & 0.11 & 1.02 & 0.41 & 0.41 & 1.02 & 1.80 & 0.08 & 0.21 & 0.16 & 10.76 \\
\hline 4 & 0.11 & 0.11 & 0.99 & 0.40 & 0.40 & 1.01 & 1.90 & 0.08 & 0.15 & 0.21 & 10.99 \\
\hline 5 & 0.10 & 0.11 & 0.98 & 0.37 & 0.38 & 0.99 & 1.73 & 0.08 & 0.16 & 0.23 & 11.09 \\
\hline 6 & 0.10 & 0.11 & 0.97 & 0.36 & 0.37 & 1.00 & 1.80 & 0.09 & 0.18 & 0.30 & 11.06 \\
\hline 7 & 0.10 & 0.11 & 0.97 & 0.36 & 0.37 & 0.98 & 2.02 & 0.09 & 0.22 & 0.35 & 11.16 \\
\hline 8 & 0.11 & 0.10 & 1.03 & 0.36 & 0.36 & 0.98 & 1.93 & 0.10 & 0.25 & 0.38 & 11.60 \\
\hline 9 & 0.12 & 0.12 & 1.02 & 0.35 & 0.35 & 1.01 & 1.92 & 0.11 & 0.43 & 0.35 & 11.78 \\
\hline High & 0.11 & 0.11 & 1.04 & 0.31 & 0.32 & 0.95 & 1.90 & 0.11 & 0.55 & 0.38 & 11.92 \\
\hline $\mathrm{H}-\mathrm{L}$ & $\begin{array}{c}0.02 \\
(2.12)\end{array}$ & $\begin{array}{c}0.01 \\
(1.89)\end{array}$ & $\begin{array}{c}0.07 \\
(0.94)\end{array}$ & $\begin{array}{c}-0.08 \\
(-5.86)\end{array}$ & $\begin{array}{l}-0.06 \\
(-4.13)\end{array}$ & $\begin{array}{c}30-0.06 \\
(-3.57)\end{array}$ & $\begin{array}{c}0.46 \\
(5.81)\end{array}$ & $\begin{array}{c}0.05 \\
(13.18)\end{array}$ & $\begin{array}{c}0.33 \\
(6.83)\end{array}$ & $\begin{array}{c}0.36 \\
(8.88)\end{array}$ & $\begin{array}{c}1.28 \\
(0.96)\end{array}$ \\
\hline
\end{tabular}




\section{Table 3: Parameter Estimates and Tests for Model Performance}

Estimates and tests are from one-stage GMM with an identity weighting matrix. The moment conditions are $\mathbb{E}\left(r_{i t+1}^{S}-r_{i t+1}^{I w}\right)=0$ for each testing portfolio $i$. $a$ is the adjustment cost parameter for tangible asset, $b$ is the adjustment cost parameter for intangible asset, $a_{2}$ is the effect of intangible asset to tangible asset, $\psi$ is the power parameter for the intangible asset adjustment cost function, $\alpha$ is capital's share. The $t$-statistics are reported in parentheses beneath the corresponding estimates. a.a.p.e. is the average absolute value pricing error in annual percent. $p\left(\chi^{2}\right)$ is the $p$-value associated with the $\chi^{2}$ statistic that tests the null hypothesis that the moment condition errors from one-stage GMM are jointly zero. $p(\lambda)$ is the $p$-value associated with the $\lambda$ test defined in Singleton (1985), comparing the performance of the $Q m$ model and the $Q u$ model. $p(\lambda)$ in row $Q m$ tests the null hypothesis that $Q m$ is the correct model while $p(\lambda)$ in row $Q u$ tests the null hypothesis that $Q u$ is the correct model. $p($ Wald $)$ is the $p$-value associated with the Wald test. $p($ Wald $)$ in row $Q u_{-} I S T C$ is for the Wald test between the $Q u_{-} I S T C$ model and the $Q u$ model while $p(W a l d)$ in row $Q u_{-} A C$ is for the Wald test between the $Q u_{-} A C$ model and the $Q u$ model. Panel A, B, and $\mathrm{C}$ report the results for the $B / M$ portfolios, the $I^{u} / K_{0}^{u}$ portfolios, and the $I^{u} / M E$ portfolios, respectively. For each panel, the results for four models are reported: the $Q m$ model, the $Q u_{-} I S T C$ model, the $Q u_{-} A C$ model, and the $Q u$ model.

\begin{tabular}{|c|c|c|c|c|c|c|c|c|c|}
\hline & \multicolumn{5}{|c|}{ Parameter Estimates } & \multicolumn{4}{|c|}{ Test Statistics } \\
\hline & $a$ & $b$ & $a_{2}$ & $\psi$ & $\alpha$ & a.a.p.e. & $p\left(\chi^{2}\right)$ & $p(\lambda)$ & $p($ Wald $)$ \\
\hline & \multicolumn{9}{|c|}{ Panel A: Ten $B / M$ portfolios } \\
\hline$Q m$ & $\begin{array}{l}43.59 \\
(0.92)\end{array}$ & & & & $\begin{array}{c}0.77 \\
(1.38)\end{array}$ & 3.88 & 0.79 & 0.00 & \\
\hline$Q u \_I S T C$ & $\begin{array}{l}16.43 \\
(0.85)\end{array}$ & & $\begin{array}{c}0.00 \\
(0.00)\end{array}$ & & $\begin{array}{c}0.44 \\
(2.32)\end{array}$ & 3.61 & 0.73 & & 1.00 \\
\hline$Q u \_A C$ & $\begin{array}{c}1.21 \\
(0.20)\end{array}$ & $\begin{array}{l}24.69 \\
(1.85)\end{array}$ & & $\begin{array}{c}1.37 \\
(3.86)\end{array}$ & $\begin{array}{c}0.40 \\
(3.35)\end{array}$ & 1.36 & 0.68 & & 0.02 \\
\hline \multirow[t]{2}{*}{$Q u$} & $\begin{array}{c}1.21 \\
(0.18)\end{array}$ & $\begin{array}{l}24.69 \\
(0.81)\end{array}$ & $\begin{array}{c}0.00 \\
(0.00)\end{array}$ & $\begin{array}{c}1.37 \\
(0.97)\end{array}$ & $\begin{array}{c}0.40 \\
(2.46)\end{array}$ & 1.36 & 0.56 & 0.98 & \\
\hline & \multicolumn{9}{|c|}{ Panel B: Ten $I^{u} / K_{0}^{u}$ portfolios } \\
\hline$Q m$ & $\begin{array}{l}13.31 \\
(1.16)\end{array}$ & & & & $\begin{array}{c}0.35 \\
(2.78)\end{array}$ & 1.93 & 0.83 & 0.00 & \\
\hline$Q u_{-} I S T C$ & $\begin{array}{c}18.70 \\
(0.79)\end{array}$ & & $\begin{array}{c}1.03 \\
(0.49)\end{array}$ & & $\begin{array}{c}0.33 \\
(2.93)\end{array}$ & 1.82 & 0.79 & & 0.00 \\
\hline$Q u_{-} A C$ & $\begin{array}{c}5.79 \\
(0.50)\end{array}$ & $\begin{array}{c}3.26 \\
(1.10)\end{array}$ & & $\begin{array}{c}4.12 \\
(0.56)\end{array}$ & $\begin{array}{c}0.31 \\
(2.39)\end{array}$ & 0.87 & 0.68 & & 0.00 \\
\hline \multirow[t]{2}{*}{$Q u$} & $\begin{array}{c}7.05 \\
(0.76)\end{array}$ & $\begin{array}{l}27.76 \\
(0.57)\end{array}$ & $\begin{array}{c}0.30 \\
(5.82)\end{array}$ & $\begin{array}{c}1.64 \\
(3.40)\end{array}$ & $\begin{array}{c}0.28 \\
(3.60)\end{array}$ & 0.49 & 0.61 & 0.98 & \\
\hline & \multicolumn{9}{|c|}{ Panel C: Ten $I^{u} / M E$ portfolios } \\
\hline$Q m$ & $\begin{array}{c}69.34 \\
(0.41)\end{array}$ & & & & $\begin{array}{c}1.00 \\
(0.54)\end{array}$ & 3.19 & 0.81 & 0.05 & \\
\hline$Q u_{-} I S T C$ & $\begin{array}{l}46.78 \\
(0.57)\end{array}$ & & $\begin{array}{c}1.35 \\
(0.65)\end{array}$ & & $\begin{array}{c}0.56 \\
(0.81)\end{array}$ & 2.44 & 0.73 & & 0.00 \\
\hline$Q u_{-} A C$ & $\begin{array}{c}1.73 \\
(0.07)\end{array}$ & $\begin{array}{c}67.47 \\
(0.07)\end{array}$ & & $\begin{array}{l}10.00 \\
(2.09)\end{array}$ & $\begin{array}{c}0.27 \\
(0.78)\end{array}$ & 5.12 & 0.68 & & 0.00 \\
\hline$Q u$ & $\begin{array}{c}2.71 \\
(0.16)\end{array}$ & $\begin{array}{l}56.20 \\
(0.93)\end{array}$ & $\begin{array}{c}0.65 \\
(5.77)\end{array}$ & $\begin{array}{c}0.59 \\
(4.90)\end{array}$ & $\begin{array}{c}0.14 \\
(1.07)\end{array}$ & 0.78 & 0.77 & 1.00 & \\
\hline
\end{tabular}




\section{Table 4: Expected Return Errors from Comparative Static Experiments}

This table reports the results from comparative static experiments. For a given portfolio, in the column denoted by $\overline{\left(I_{t+1} / K_{t+1}\right)}$, we report the a.a.p.e. calculated by setting $I_{t+1} / K_{t+1}$ to its cross sectional average value at time $t+1$ and $I_{t} / K_{t}$ to its cross sectional average value at time $t$. We use parameters reported in Table 3 for the $Q u$ model to reconstruct the expected return. The difference between these reconstructed expected return and the realized return for each portfolio, the high-minus-low portfolio and the average absolute pricing errors are then reported. The results for others columns are designed analogously. Panels $\mathrm{A}, \mathrm{B}$, and $\mathrm{C}$ report the results for the ten $B / M$ portfolios, the ten $I^{u} / K_{0}^{u}$ portfolios, and the ten $I^{u} / M E$ portfolios, respectively.

\begin{tabular}{|c|c|c|c|c|c|}
\hline & $\overline{\left(\frac{I_{t+1}^{m}}{K_{t+1}^{m}}\right)}, \overline{\left(\frac{I_{t}^{m}}{K_{t}^{m}}\right)}$ & $\overline{\left(\frac{I_{t}^{u}}{K_{t}^{u}}\right)}$ & $\overline{\left(\frac{K_{t+1}^{u}}{K_{t+1}^{m}}\right)}$ & $\overline{\left(\frac{Y_{t+1}}{K_{t+1}^{m}}\right)}$ & $\bar{w}$ \\
\hline & \multicolumn{5}{|c|}{ Panel A: Ten $B / M$ portfolios } \\
\hline Low & 1.97 & -9.95 & -10.48 & -3.44 & -4.93 \\
\hline 2 & 0.73 & -4.54 & -4.74 & -0.88 & -1.96 \\
\hline 3 & -2.97 & -4.80 & -4.84 & -0.38 & -0.99 \\
\hline 4 & 1.64 & 1.95 & 1.82 & 2.73 & 1.93 \\
\hline 5 & -1.49 & -0.23 & -0.07 & 0.92 & 1.12 \\
\hline 6 & 0.07 & 4.92 & 5.06 & 2.45 & 3.06 \\
\hline 7 & -0.92 & 5.51 & 5.37 & 1.65 & 2.21 \\
\hline 8 & -1.90 & 9.14 & 9.47 & 2.48 & 4.43 \\
\hline 9 & -0.27 & 9.78 & 9.72 & 4.03 & 6.23 \\
\hline High & 2.76 & 10.70 & 11.25 & 9.21 & 10.21 \\
\hline $\mathrm{H}-\mathrm{L}$ & 0.79 & 20.65 & 21.73 & 12.65 & 15.14 \\
\hline \multirow[t]{2}{*}{ a.a.p.e. } & 1.47 & 6.15 & 6.28 & 2.82 & 3.71 \\
\hline & \multicolumn{5}{|c|}{ Panel B: Ten $I^{u} / K_{0}^{u}$ portfolios } \\
\hline Low & 4.13 & 2.41 & 5.85 & 3.95 & 4.83 \\
\hline 2 & 3.41 & 3.30 & 6.10 & 2.39 & 3.44 \\
\hline 3 & 1.87 & 1.63 & 3.44 & 0.19 & 1.89 \\
\hline 4 & -0.71 & -0.60 & 0.25 & -1.97 & -0.98 \\
\hline 5 & 0.63 & 0.28 & 0.91 & -1.40 & -0.77 \\
\hline 6 & 2.41 & 1.85 & 0.76 & 0.42 & 1.08 \\
\hline 7 & 2.15 & 2.08 & 1.41 & 2.24 & 1.49 \\
\hline 8 & 0.47 & 0.43 & 0.12 & 0.88 & 0.11 \\
\hline 9 & 0.21 & -0.06 & -2.88 & 0.28 & -0.51 \\
\hline High & -4.71 & -6.14 & -7.97 & -2.08 & -3.17 \\
\hline $\mathrm{H}-\mathrm{L}$ & -8.84 & -8.54 & -13.82 & -6.03 & -8.00 \\
\hline \multirow[t]{2}{*}{ a.a.p.e. } & 2.07 & 1.88 & 2.97 & 1.58 & 1.83 \\
\hline & \multicolumn{5}{|c|}{ Panel C: Ten $I^{u} / M E$ portfolios } \\
\hline Low & -0.45 & -8.75 & -8.85 & -9.48 & -10.22 \\
\hline 2 & 2.00 & -4.61 & -4.73 & -5.94 & -6.62 \\
\hline 3 & -1.01 & -3.75 & -3.62 & -3.85 & -4.79 \\
\hline 4 & -1.63 & -2.52 & -2.51 & -2.29 & -3.88 \\
\hline 5 & -1.68 & -1.99 & -2.00 & -2.11 & -3.54 \\
\hline 6 & 1.78 & 2.11 & 2.01 & 1.97 & 0.97 \\
\hline 7 & 0.30 & 0.87 & 0.85 & 1.34 & 1.13 \\
\hline 8 & -0.31 & 0.32 & 0.49 & 0.80 & 1.80 \\
\hline 9 & 1.18 & 1.84 & 1.92 & 2.56 & 9.95 \\
\hline High & 5.12 & 5.69 & 5.56 & 5.66 & 15.61 \\
\hline $\mathrm{H}-\mathrm{L}$ & 5.57 & 13.44 & 14.41 & 15.14 & 25.83 \\
\hline a.a.p.e. & 1.55 & 3.24 & 3.25 & 3.60 & 5.85 \\
\hline
\end{tabular}




\section{Table 5: The Adjustment-Costs-to-Investment $(A C / I)$ Ratio}

This table reports the adjustment-costs-to-investment $(A C / I)$ ratios estimated using the ten $B / M$ portfolios, the ten $I^{u} / K_{0}^{u}$ portfolios, and the ten $I^{u} / M E$ portfolios, respectively, for both tangible investments and intangible investments, based on the parameter estimate in Table 3. For tangible investments, we report the estimates based on both the $Q m$ model and the $Q u$ model. For intangible investments, we report the estimate based on the $Q u$ model only.

\begin{tabular}{|c|c|c|c|c|}
\hline & $B / M$ portfolios & $I^{u} / K_{0}^{u}$ portfolios & $I^{u} / M E$ portfolios & Average \\
\hline$A C^{m} / I^{m}(Q m)$ & $232 \%$ & $73.7 \%$ & $362 \%$ & $223 \%$ \\
\hline$A C^{m} / I^{m}(Q u)$ & $6.43 \%$ & $39.05 \%$ & $14.17 \%$ & $19.88 \%$ \\
\hline$A C^{u} / I^{u}(Q u)$ & $839 \%$ & $589 \%$ & $5,708 \%$ & $2,379 \%$ \\
\hline
\end{tabular}




\section{Figure 1: Fitted Average Return vs. Realized Average Return: The $B / M$ Portfolios}

Average predicted stock returns versus average realized stock returns for the $B / M$ portfolios, using the $q$-theory model with only tangible assets $(Q m)$, the IAA $q$-theory model with the ISTC effect $\left(Q u \_I S T C\right)$, the IAA $q$-theory model with the AC effect $\left(Q u_{-} A C\right)$, and the IAA $q$-theory model with both the ISTC and the AC effects $(Q u)$, respectively. Each number in the figure represents one portfolio (1 lowest, 10 highest).
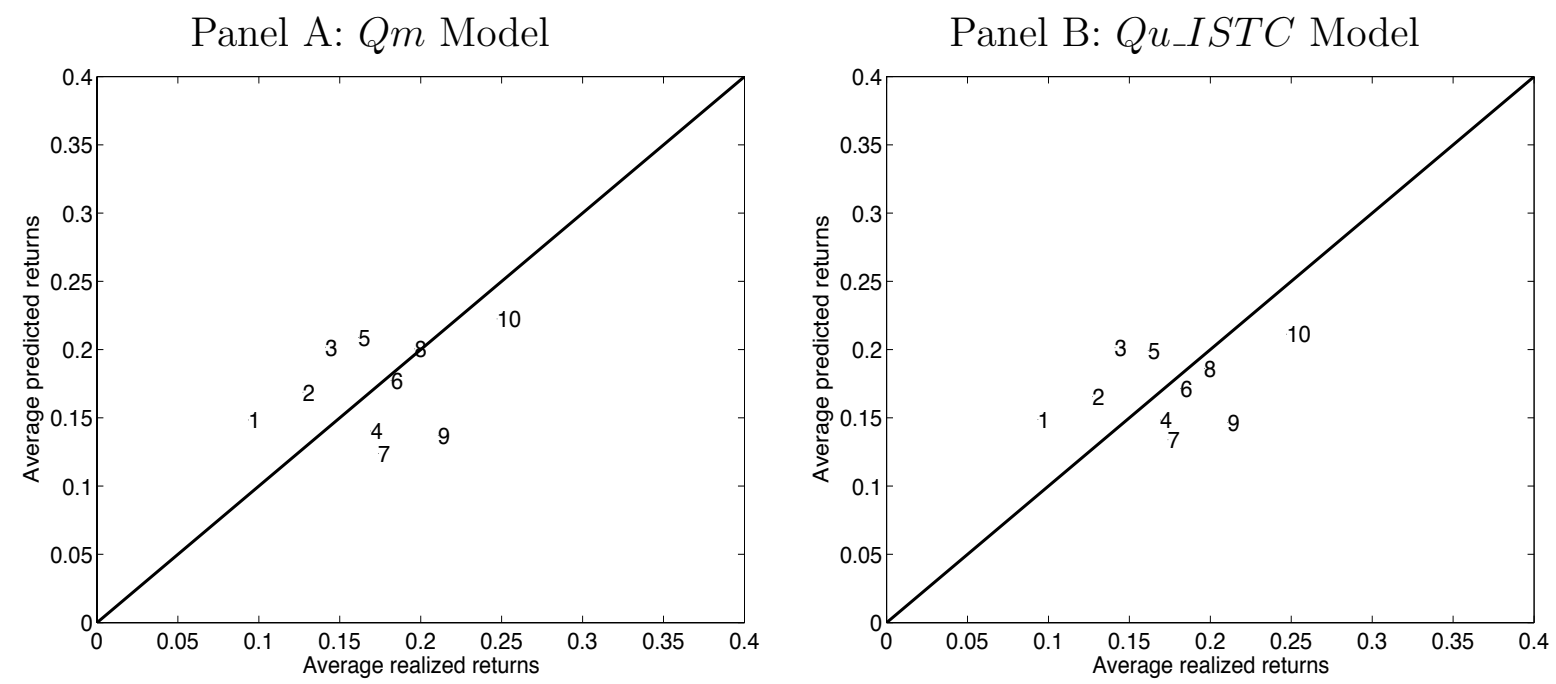

Panel C: $Q u \_A C$ Model
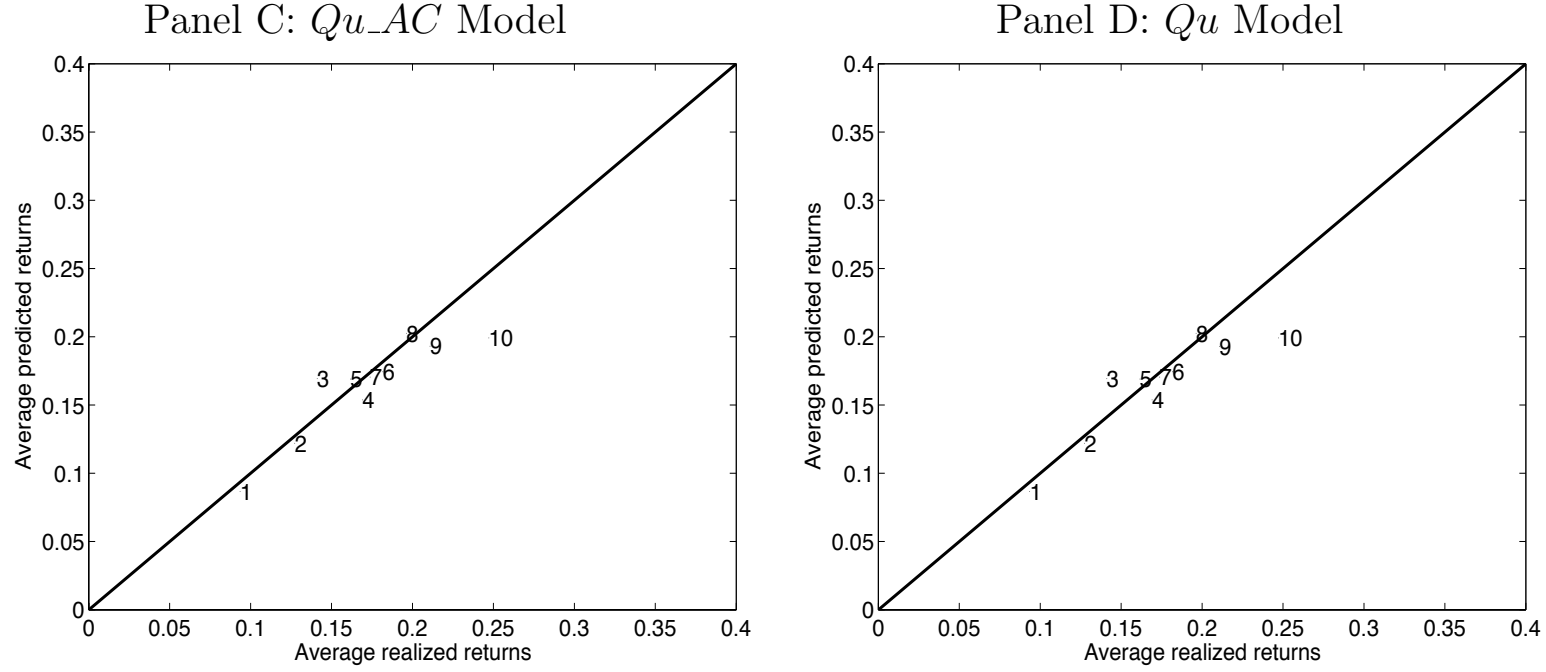


\section{Figure 2: Fitted Average Return vs. Realized Average Return: The $I^{u} / K_{0}^{u}$ Portfolios}

Average predicted stock returns versus average realized stock returns for the $I^{u} / K_{0}^{u}$ portfolios, using the $q$-theory model with only tangible assets $(Q m)$, the IAA $q$-theory model with the ISTC effect $\left(Q u \_I S T C\right)$, the IAA $q$-theory model with the AC effect $\left(Q u_{-} A C\right)$, and the IAA $q$-theory model with both the ISTC and the AC effects $(Q u)$, respectively. Each number in the figure represents one portfolio (1 lowest, 10 highest).
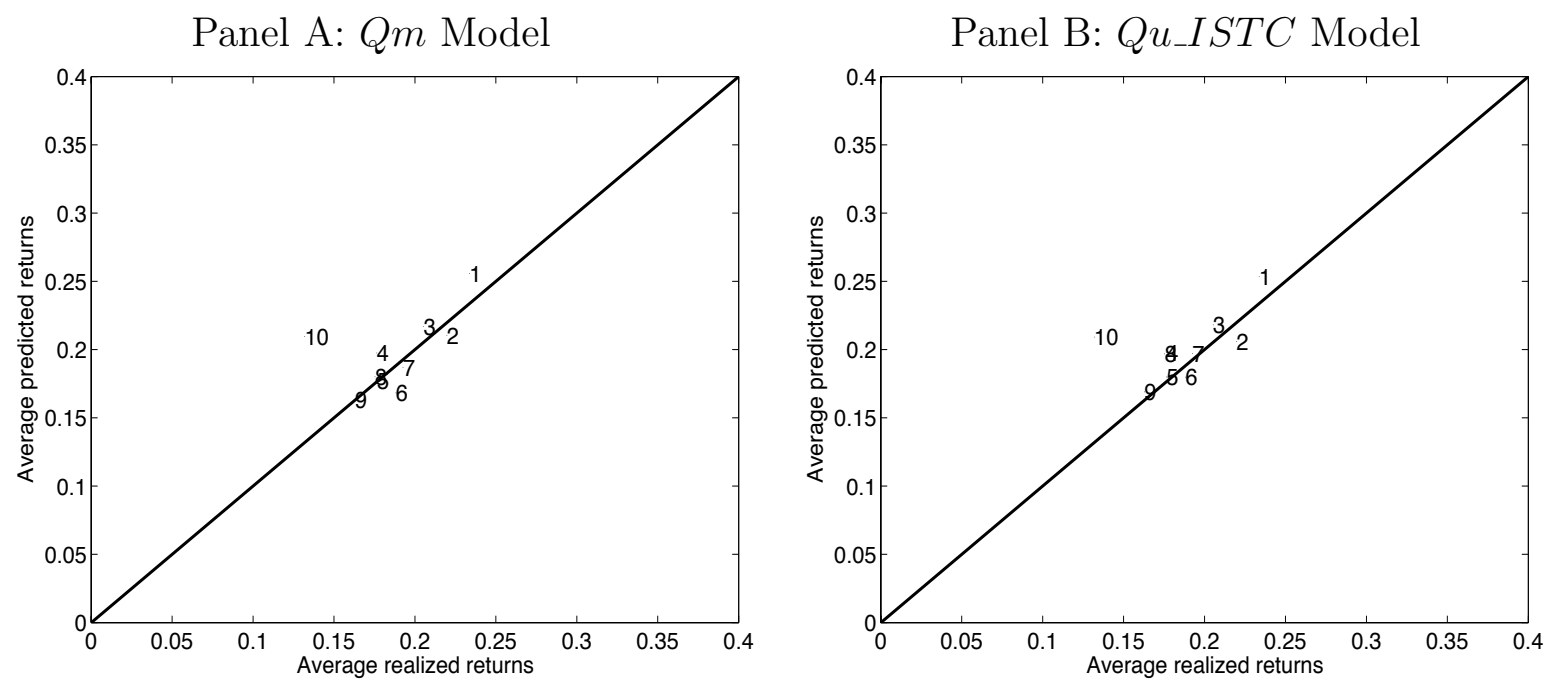

Panel C: $Q u_{-} A C$ Model

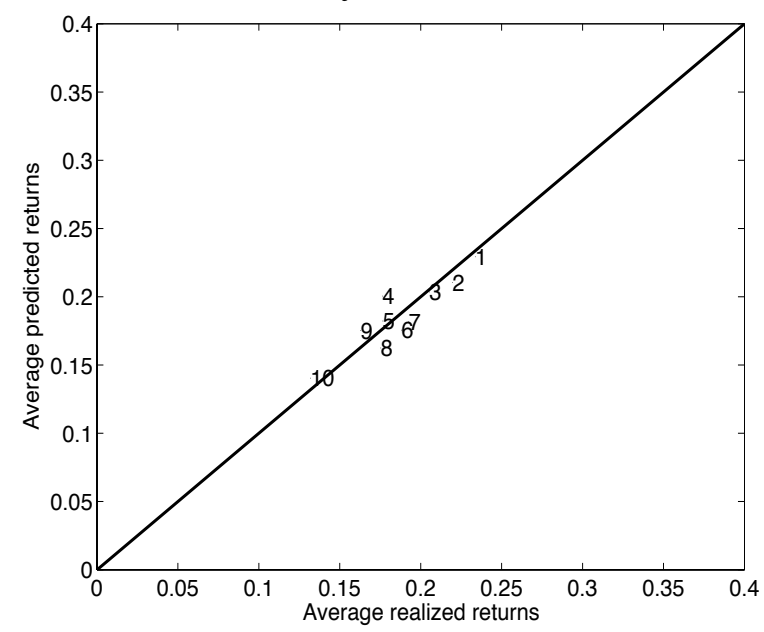

Panel D: $Q u$ Model

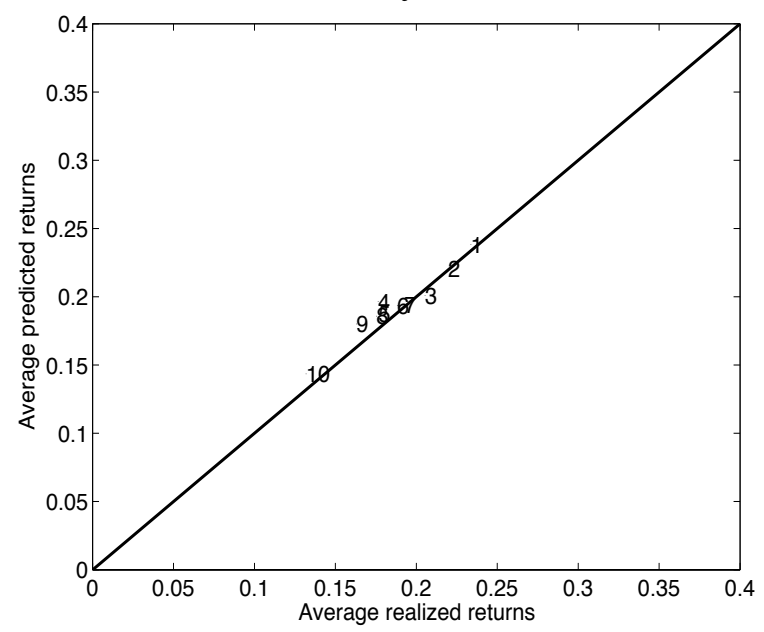




\section{Figure 3: Fitted Average Return vs. Realized Average Return: The $I^{u} / M E$ Portfolios}

Average predicted stock returns versus average realized stock returns for the $I^{u} / M E$ portfolios, using the $q$-theory model with only tangible assets $(Q m)$, the IAA $q$-theory model with the ISTC effect $\left(Q u \_I S T C\right)$, the IAA $q$-theory model with the AC effect $\left(Q u_{-} A C\right)$, and the IAA $q$-theory model with both the ISTC and the AC effects $(Q u)$, respectively. Each number in the figure represents one portfolio (1 lowest, 10 highest).
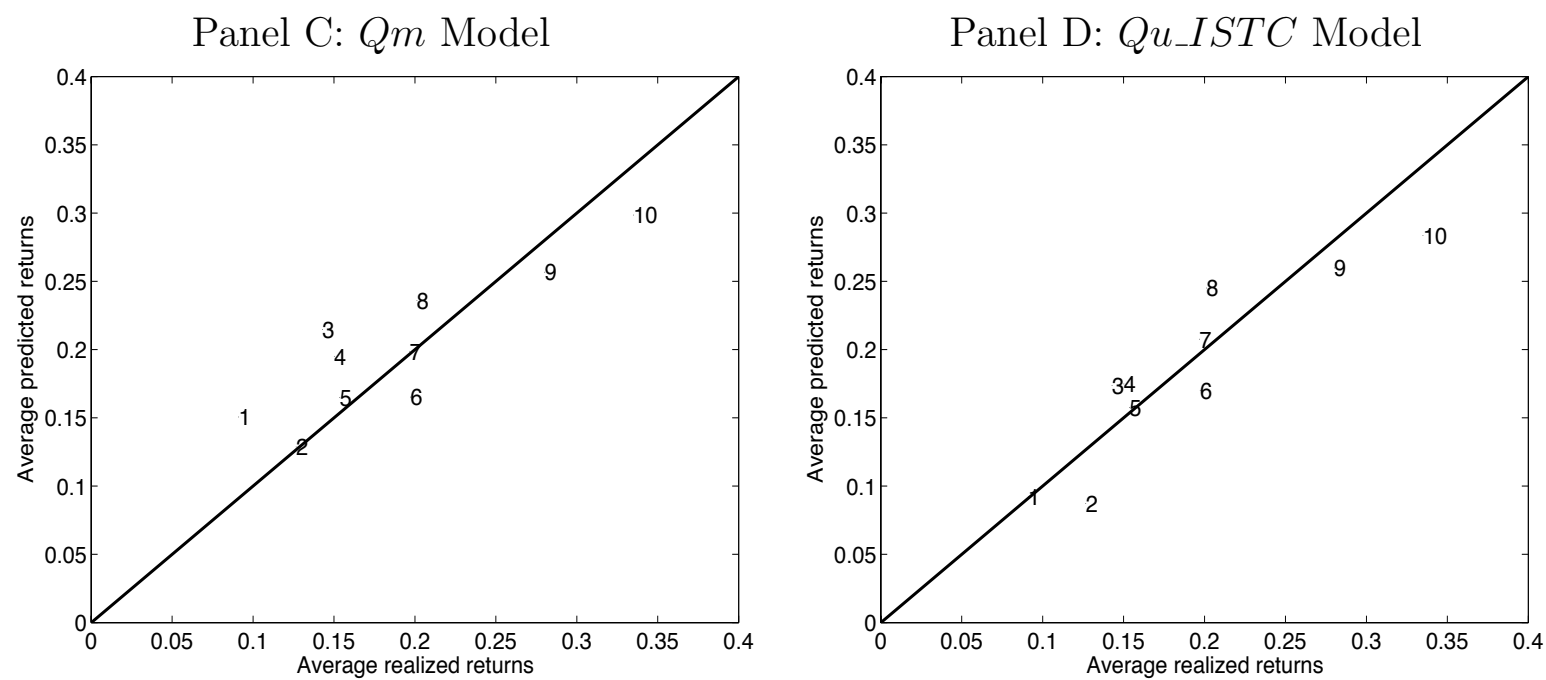

Panel E: $Q u \_A C$ Model

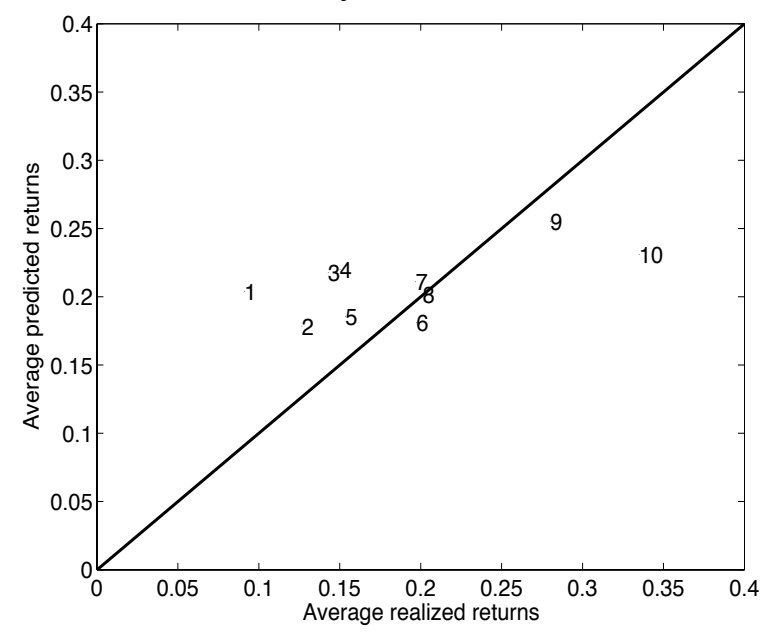

Panel F: $Q u$ Model

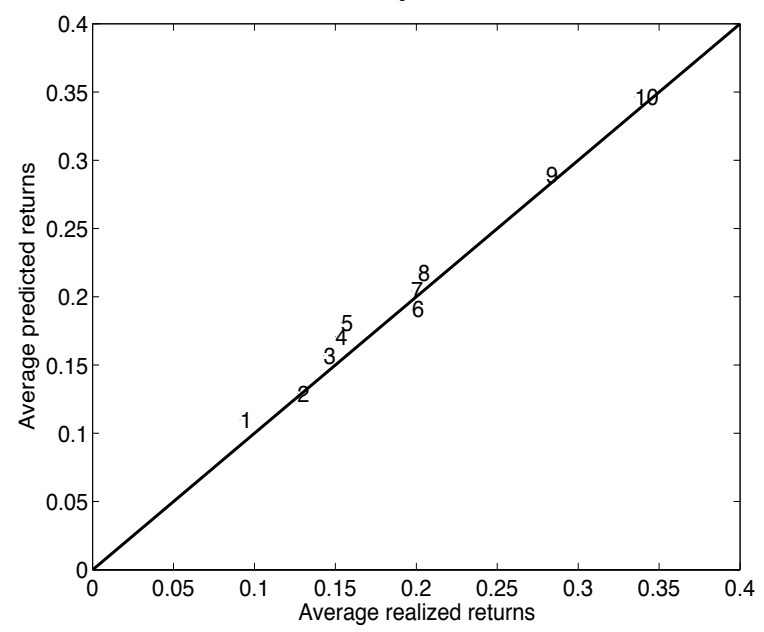

